\title{
An extended MAIRCA method using intuitionistic fuzzy sets for coronavirus vaccine selection in the age of COVID-19
}

\author{
Fatih Ecer ${ }^{1}$ (10)
}

Received: 30 June 2021 / Accepted: 2 November 2021 / Published online: 7 January 2022

(C) The Author(s), under exclusive licence to Springer-Verlag London Ltd., part of Springer Nature 2021

\begin{abstract}
All over the world, the COVID-19 outbreak seriously affects life, whereas numerous people have infected and passed away. To control the spread of it and to protect people, appreciable vaccine development efforts continue with increasing momentum. Given that this pandemic will be in our lives for a long time, it is obvious that a reliable and useful framework is needed to choose among coronavirus vaccines. To this end, this paper proposes a new intuitionistic fuzzy extension of MAIRCA framework, named intuitionistic fuzzy MAIRCA (IF-MAIRCA) to assess coronavirus vaccines according to some evaluation criteria. Based on the group decision-making, the IF-MAIRCA framework both extracts the criteria weights and discovers the prioritization of the alternatives under uncertainty. In this work, as a case study, five coronavirus vaccines approved by the world's leading authorities are evaluated according to various criteria. The findings demonstrate that the most significant criteria considered in coronavirus vaccine selection are "duration of protection," "effectiveness of the vaccine," "success against the mutations," and "logistics," respectively, whereas the best coronavirus vaccine is AZD1222. Apart from this, the proposed model's robustness is verified with a three-phase sensitivity analysis.
\end{abstract}

Keywords Coronavirus vaccine · MCGDM - Intuitionistic fuzzy sets · IF-MAIRCA · Coronavirus vaccine selection · MAIRCA

\section{Introduction}

The emergence in 2019 of a new coronavirus, SARS-CoV2 (COVID-19), has made devastating and huge consequences worldwide. Although some control mechanisms like hand hygiene, use of masks, and physical distancing [22] have helped decrease the transmission, unfortunately, these measures have failed to prevent the spread of COVID-19. As of 23 September 2021, as per Johns Hopkins University report (Johns Hopkins University and Medicine, 2021), 230,898,440 individuals have been infected, and 4,733,154 persons passed away due to this outbreak globally. Vaccines are required to reduce the complications and deaths associated with COVID-19, as can be expected, thus some vaccine candidates have started

Fatih Ecer

fecer@aku.edu.tr

1 Department of Business Administrative, Faculty of Economics and Administrative Sciences, Afyon Kocatepe University, 03030 Afyonkarahisar, Turkey to emerge recently thanks to the extraordinary efforts of scholars [12].

The World Health Organization (WHO) has set the lower limit of the efficacy rate of a coronavirus vaccine at 50 percent [88]. In other words, in the era of COVID-19, each vaccine that is declared to provide protection above this rate is considered successful. Accordingly, to date, some coronavirus vaccines such as Comirnaty (BNT162b2), mRNA-1273, AZD1222, CoronaVac, and Sputnik V managed to obtain emergency use approval from the European Medicines Agency (EMA), the American Food and Drug Administration (FDA), and the WHO.

Obviously, the demand for vaccines will soar as long as the COVID-19 pandemic remains harsh. Questions about which vaccine is better are at present on the world agenda. Nevertheless, the available information on both existing coronavirus vaccines and COVID-19 is insufficient to respond to such a question. In parallel to the increase in vaccine production in the near future, should it be easier to reach different vaccines, it is no doubt that policymakers and customers will ask to choose the best vaccine against 
the COVID-19 illness. However, selecting a coronavirus vaccine is a challenging problem that encompasses numerous quantitative and qualitative attributes and alternatives together. Fortunately, the MCDM terminology has unique methods that allow to reliably solve such problems. Despite the fact that the $\boldsymbol{M u l t i}-\boldsymbol{A}$ ttribute $\boldsymbol{I d e a l}-\boldsymbol{R}$ eal $\boldsymbol{C o m}$ parative Analysis (MAIRCA) method was recently introduced by Pamucar et al. [65], it has attracted great attention from researchers. It is based on defining the difference between theoretical and actual outcomes. Thanks to a unique linear normalization algorithm, the main advantage of MAIRCA, one can obtain very reliable results. Further, MAIRCA is an effective mathematical tool and solution method that allows combining with other methods. However, assessments via exact numbers are not very sufficient in expressing human thoughts and opinions. Put it differently, the MAIRCA method cannot express experts' vagueness and ambiguity appropriately. To overcome such shortcomings, the fuzzy set theory proposed by Zadeh [99] presents rather useful tools [27]. After Zadeh's fuzzy sets, on the other hand, there have been some attempts to model uncertainty in a more realistic way [30]. As a result of the intense efforts of the researchers, some extensions of fuzzy sets have been developed $[19,63]$. Intuitionistic fuzzy sets (IFSs), as an extension of the theory of fuzzy sets, were introduced by Atanassov [9] both to perform more flexible evaluations and to model imprecision properly. IFSs are also helpful to depict the ambiguous reasoning of experts. They yield a proper approach for coping with decisionmaking procedures containing membership and nonmembership degrees as well as hesitation degrees. In a nutshell, with IFSs, the opinions of individuals are stated more inclusively since vagueness and imprecisions are identified by both the membership and non-membership degrees, simultaneously. According to existing literature, we discovered that no study had focused on the development of multi-criteria field integrated with IFS concept and aimed to assess coronavirus vaccines. For instance, Yener and Can [95] proposed the IF Multi-Attribute Border Approximation Area (IF-MABAC) approach for risk assessment. For assessing sustainable development indicators, Alrasheedi et al. [5] suggested the Combined Compromise Solution (CoCoSo) method with IF concept. IF best-worst analytic hierarchy process was recently introduced by Majumder et al. [52] for efficiency analysis. Rani et al. used an IF-gray relational analysis (IF-GRA) approach for selecting service providers. A combination of IFs and the combinative distance-based assessment (CODAS) technique was introduced by Mishra et al. [55] to evaluate sustainable suppliers. Ziquan et al. [103] employed the stepwise weight assessment ratio analysis (SWARA) and the complex proportional assessment (COPRAS) method under IF environment for determining the finest supplier. In this work, dissimilar to other studies, a framework based on group decision-making and developing from the integration of the MAIRCA method and IFSs is proposed, named the intuitionistic fuzzy MAIRCA (IF-MAIRCA) methodology for coronavirus vaccine selection problem for a real-life case study. Consequently, the IF-MAIRCA framework can cope with vague and indeterminate information in a satisfactory way in multicriteria real-life problems.

Application of MCDM in COVID-19 outbreak is still at a very early stage. Hezam et al. [37] determined the priority group for the COVID-19 vaccine via an integrated neutrosophic analytical hierarch process (AHP) and technique for order of preference by similarity to ideal solution (TOPSIS) approach. By using measurement of alternatives and ranking according to the compromise solution under IF environment (IF-MARCOS), Ecer and Dragan (2021) evaluated healthcare services of insurance companies during the COVID-19 epidemic. Maqbool and Khan [53] analyzed barriers to prevent the transmission of COVID-19 illness through decision-making trial and evaluation laboratory (DEMATEL). In spite of these efforts, the research questions below remain unanswered:

Q1. Which methodology is most proper for a comprehensive evaluation of coronavirus vaccines during the COVID-19 epidemic?

Q2. How can policymakers and authorities as well as customers choose their coronavirus vaccines reliably and scientifically?

Q3. Which criteria are more appropriate for coronavirus vaccine selection?

Below are the main motivations for this paper.

- Because IFSs include a non-membership function, vagueness and uncertainty can be coped with more conveniently. Besides, IFSs are suitable vehicles to be utilized for describing ambiguous or vague decision information.

- The modifications of the MAIRCA technique and operators of IFSs are performed to introduce the fused model.

- A multi-criteria problem regarding the coronavirus vaccine selection is given and solved by employing the suggested MAIRCA approach, which discloses the properness of the methodology proposed in this work.

Motivated by the above reasons, this research has the following goals:

- To identify evaluation criteria of coronavirus vaccine assessment;

- To weigh the criteria of coronavirus vaccine selection;

- To evaluate coronavirus vaccines approved in the age of COVID-19. 
The research is structured as follows. An extensive literature survey is presented in Sect. 2. Section 3 turns to the methodological subject. Particularly, preliminary knowledge on IFSs is discussed briefly. However, the introduced framework is explained in detail. A case study is introduced in the next section. Section 5 presents a comprehensive sensitivity analysis. The penultimate section conducts managerial implications and limitations. Conclusions are drawn in Sect. 7.

\section{Review of earlier work}

The literature section is grouped into two subsections. The first part of the literature survey aims to summarize the papers that employed the MAIRCA technique, while its second part focuses on the research related to any MCDM technique under the IFS.

\subsection{Studies using the MAIRCA method}

Given that the enormous potential of MCDM, lots of MCDM techniques have been posited so far to solve multicriteria problems like MAIRCA. Due to the following superiorities of the MAIRCA technique, this work prefers MAIRCA: (i) it can be employed problems where there are numerous evaluation criteria and alternatives, (ii) it is capable of solving problems having both qualitative and quantitative evaluation criteria, (iii) it is easy to understand and apply, and (iv) it produces consistent solutions due to its own algorithm.

After the first study conducted by Pamucar et al. [65], till now, several studies have presented in the MCDM literature that utilize the MAIRCA method's superiorities, such as for selecting ammunition depots [33], assessing financial performance [11, 36], neighborhood selection [104], supplier selection [29, 59], selecting catering firm [85], site selection [61], etc.

However, the traditional MAIRCA technique is limited by its utilize of solely numerical values when prioritizing the alternatives according to the evaluation criteria; thus, extending MAIRCA to deal with the fuzziness and uncertainty of human thought is of practical importance. Pamucar et al. [64], for example, developed a model including DEMATEL, ANP, and MAIRCA techniques in the context of interval rough numbers to cope with a bidder evaluation problem. To evaluate suppliers, Chatterjee et al. [24] applied rough DEMATEL and rough ANP as well as rough MAIRCA. Pamucar et al. [60] suggested an intervalvalued fuzzy-rough MAIRCA methodology for the treatment of vagueness. Boral et al. [15] introduced an AHP and MAIRCA methodology under a fuzzy environment. A combined fuzzy BWM and fuzzy MAIRCA approach developed by Gul and Ak [34] for the evaluation of occupational risks in terms of human health and the environment.

\subsection{MCDM techniques under IF environment}

On the basis of integration, several decision-making methodologies have been provided to solve real-world problems in an IF environment, such as third-party logistics evaluation [86], cost optimization [84], supplier selection [87, 89], module selection [51], sustainable performance evaluation [45], machine selection [4], job appointment [83], partner selection [97], technology evaluation [17], etc. To help waste managers, Karagoz et al. [40] introduced the intuitionistic combinative distance-based assessment (IF-CODAS) approach. By combining the AHP technique and the axiomatic design, Büyüközkan and Göçer [20] provided a methodology for solving supplier selection problem in IF concept. Using quality function deployment (QFD) and TOPSIS for knowledge management system evaluation in an IF environment, $\mathrm{Li}$ et al. [47] suggested a novel fuzzy MCDM model. Table 1 demonstrates a summary of researches in relation to MCDM techniques in IF context recently.

With respect to the detailed literature survey, therefore, the following gaps are revealed:

- To the best of the authors' knowledge, there is no earlier work that has used the IF-MAIRCA approach. Some extensions of MAIRCA intending to contain more ambiguity are available in the literature $[3,13]$. However, the IF extension of the method has not been performed yet.

- There is no work on the performance evaluation of coronavirus vaccines according to various qualitative and quantitative attributes.

Keeping in mind the matters discussed above, this paper focuses on the coronavirus vaccine evaluation and selection problem. Since this problem has multiple vagueness, in this work, the MAIRCA method under an intuitionistic fuzzy environment is introduced for the coronavirus vaccine problem.

\section{Research methodology}

\subsection{IFSs and related knowledge}

Zadeh's fuzzy sets [99] copes with vagueness successfully in a scientifically style. Yet, it can solely focus on the membership degree of undefined cases [28, 62]. Besides, it fails in coping with the non-membership degree of uncertain conditions. To eliminate this problem, Atanassov [9] 
Table 1 MCDM studies based on IFSs

\begin{tabular}{|c|c|c|c|}
\hline Author/s & Goal & Method utilized & $\begin{array}{l}\text { Type of } \\
\text { application }\end{array}$ \\
\hline Alrasheedi et al. [5] & Green growth indicators' assessment & IVIF-CoCoSo & $\begin{array}{l}\text { Illustrative } \\
\text { example }\end{array}$ \\
\hline Ecer and Pamucar [31] & $\begin{array}{l}\text { Evaluation of health services of insurance } \\
\text { companies }\end{array}$ & IF-MARCOS & Case study \\
\hline Rouyendegh et al. [71] & Green supplier selection & IF-TOPSIS & Case study \\
\hline Karaşan et al. [41] & Electric vehicles charging stations' evaluation & IF-DEMATEL, IF-AHP, IF-TOPSIS & Case study \\
\hline Mishra et al. [56] & $\begin{array}{l}\text { Sustainability assessment of bioenergy production } \\
\text { process }\end{array}$ & IF-SWARA, IF-COPRAS & Case study \\
\hline Xiong et al. [91] & Resilient-green supplier selection & IF-BWM & $\begin{array}{l}\text { Illustrative } \\
\text { example }\end{array}$ \\
\hline Liu et al. [49] & Blockchain service provider selection & IF-Entropy, IF-TOPSIS & $\begin{array}{l}\text { Illustrative } \\
\text { example }\end{array}$ \\
\hline Zhang et al. [100] & Energy storage technology evaluation & IF-MULTIMOORA & Case study \\
\hline Çalı et al. (2019) & Supplier selection & IF-ELECTRE, IF-VIKOR & $\begin{array}{l}\text { Illustrative } \\
\text { example }\end{array}$ \\
\hline Yeni and Özçelik [96] & Personnel selection problem & IF-CODAS & $\begin{array}{l}\text { Illustrative } \\
\text { example }\end{array}$ \\
\hline Kumar and Haleem [46] & Innovativeness assessment & IF-TOPSIS & $\begin{array}{l}\text { Illustrative } \\
\text { example }\end{array}$ \\
\hline Schitea et al. [73] & Hydrogen mobility roll-up site selection & IF-WASPAS, IF-COPRAS, IF-EDAS & Case study \\
\hline Rani et al. [67] & Senior executive selection & IF-TODIM & $\begin{array}{l}\text { Illustrative } \\
\text { example }\end{array}$ \\
\hline Shen et al. [75] & Credit risk evaluation & IF-TOPSIS & $\begin{array}{l}\text { Illustrative } \\
\text { example }\end{array}$ \\
\hline $\begin{array}{l}\text { Stanujkić and Karabašević } \\
\text { [79] }\end{array}$ & Website evaluation & IF-WASPAS & $\begin{array}{l}\text { Illustrative } \\
\text { example }\end{array}$ \\
\hline Liao et al. [48] & Beverage selection & IF-ANP & Case study \\
\hline Mishra and Rani [54] & Reservoir Flood Control & IVIF-WASPAS & $\begin{array}{c}\text { Illustrative } \\
\text { example }\end{array}$ \\
\hline Sen et al. [74] & Sustainable supplier selection & IF-MOORA, IF-GRA, IF-TOPSIS & Case study \\
\hline Tian et al. [82] & Green supplier selection & IF-BWM, IF-TOPSIS & Case study \\
\hline Kahraman et al. [39] & Solid waste disposal site selection & IF-EDAS & $\begin{array}{l}\text { Illustrative } \\
\text { example }\end{array}$ \\
\hline Zhao et al. [102] & Supplier selection & IF-VIKOR & $\begin{array}{l}\text { Illustrative } \\
\text { example }\end{array}$ \\
\hline Abdullah and Najib [1] & System index evaluation & IF-AHP & $\begin{array}{l}\text { Illustrative } \\
\text { example }\end{array}$ \\
\hline Gumus et al. [35] & Sustainable energy planning & IF-Entropy, IF-TOPSIS & Case study \\
\hline Xue et al. [93] & Material selection & IVIF-MABAC & $\begin{array}{l}\text { Illustrative } \\
\text { example }\end{array}$ \\
\hline Joshi and Kumar [38] & Portfolio selection problem & IF-Entropy, IF-TOPSIS & Case study \\
\hline Baležentis et al. [14] & Personnel selection & IF-MULTIMOORA & $\begin{array}{l}\text { Illustrative } \\
\text { example }\end{array}$ \\
\hline Devi and Yadav [26] & Plant location selection & IF-ELECTRE & $\begin{array}{l}\text { Illustrative } \\
\text { example }\end{array}$ \\
\hline Krohling et al. [44] & Supplier selection & IF-TODIM & Case study \\
\hline Chai et al. [23] & Supplier selection & $\begin{array}{l}\text { IF-Superiority and Inferiority Ranking } \\
\text { (IF-SIR) }\end{array}$ & $\begin{array}{l}\text { Illustrative } \\
\text { example }\end{array}$ \\
\hline Tan $[81]$ & Investment decisions & IF-TOPSIS & $\begin{array}{l}\text { Illustrative } \\
\text { example }\end{array}$ \\
\hline Zhang and Liu [101] & System analysis engineer evaluation & IF-Entropy, IF-GRA & $\begin{array}{l}\text { Illustrative } \\
\text { example }\end{array}$ \\
\hline
\end{tabular}


Table 1 (continued)

\begin{tabular}{lllr}
\hline Author/s & Goal & Method utilized & $\begin{array}{c}\text { Type of } \\
\text { application }\end{array}$ \\
\hline Ye [94] & Virtual enterprise partner selection & IF-TOPSIS & $\begin{array}{c}\text { Illustrative } \\
\text { example }\end{array}$ \\
Ashtiani et al. [6] & R\&D manager selection & IF-TOPSIS & Illustrative \\
example & Illustrative \\
example
\end{tabular}

presented IFSs as a useful way of employing uncertainty and fuzziness by means of the degree of hesitation in the system. To better understand the following part, IFS is clarified below [10].

Let a set $X$ be a fixed universe of discourse and its subset $A=\left\{x, \mu_{A}(x), \vartheta_{A}(x) \mid x \in X\right\}$ which is allocated by the membership function $\mu_{A}(x)=[0,1]$ and non-membership function $\vartheta_{A}(x)=[0,1]$, satisfying $0 \leq \mu_{A}(x)+\vartheta_{A}(x) \leq 1$. Additionally, for each IFS A, $\pi_{A}=1-\mu_{A}(x)-\vartheta_{A}(x)$ which corresponds to the degree of hesitancy. It is obvious that $0 \leq \pi_{A}(x) \leq 1$.

\subsection{Intuitionistic fuzzy MAIRCA (IF-MAIRCA)}

In the present work, it is applied to the MCDM technique to derive the weight value of each attribute as per the IF method and IF weighted averaging (IFWA) operator proposed by $\mathrm{Xu}$ [92], and the linguistic phrases are transformed into intuitionistic fuzzy numbers (IFNs). The description IF-MAIRCA framework can be carried out as follows.

(i) $e=\{1,2, \ldots, k\}$ is the set of experts and their weights are $\varphi=\left[\varphi_{1}, \varphi_{2}, \ldots, \varphi_{k}\right]$ and $\sum_{e=1}^{k} \varphi_{e}=1$. The importance weight of each expert is computed by Eq. (1).

$\varphi_{e}=\frac{\left(\mu_{e}+\pi_{e} \cdot\left(\frac{\mu_{e}}{\mu_{e}+\vartheta_{e}}\right)\right)}{\sum_{e=1}^{k}\left(\mu_{e}+\pi_{k} \cdot\left(\frac{\mu_{e}}{\mu_{e}+\vartheta_{e}}\right)\right)}$

In Eq. (1), $\mu, \vartheta$, and $\pi$ represent membership function, non-membership function, and hesitancy degree, respectively.

(ii) $C_{m}$ is the number of criteria and their weights are $W=\left[w_{1}, w_{2}, \ldots, w_{n}\right]$,

where $\sum_{m=1}^{n} w_{m}=1 ; m=1,2, \ldots, n$.

Step 1. Determining importance weights of experts.

The linguistic evaluations for both the experts and evaluation criteria are carried out via Table 2.

Step 2. Construct the aggregated IF decision matrix.
Table 2 Linguistic phrases for a rating of experts and evaluation criteria [73]

\begin{tabular}{lc}
\hline Phrase & IFNs $(\mu, \vartheta)$ \\
\hline Very important (VI) & $(0.88,0.08)$ \\
Important (I) & $(0.75,0.20)$ \\
Medium (M) & $(0.50,0.45)$ \\
Unimportant (UI) & $(0.35,0.60)$ \\
Very unimportant (VU) & $(0.08,0.88)$ \\
\hline
\end{tabular}

Let $D=\left[P_{\mathrm{me}}\right]_{n * k}(e=1,2, \ldots, k ; m=1,2, \ldots, n)$ be the IF decision matrix of experts. Herein, $P_{\text {me }}$ expresses the assessment of $d$ th about expert the $j$ th criteria. $P_{\text {me }}$ is used by IFN, and it can be stated that $P_{\mathrm{me}}=\left(\mu_{P_{\mathrm{me}}}, \vartheta_{P_{\mathrm{me}}}, \pi_{P_{\mathrm{me}}}\right)$ where $\pi_{S_{j d}}$ is the hesitation degree of $\pi_{\mathrm{me}}$ is performed by Eq. (2).

$\pi_{\mathrm{me}}=1-\mu_{P_{\mathrm{me}}}-\vartheta_{P_{\mathrm{me}}}$

The aggregated IF decision matrix is depicted as $\hat{R}=\left[\hat{P}_{\mathrm{me}}\right]_{n * k}$

$$
\begin{aligned}
\hat{P}_{m} & =\operatorname{IFWA}_{w}\left(P_{m 1}, P_{m 2}, \ldots, P_{\mathrm{me}}\right)= \\
& {\left[1-\prod_{e=1}^{k}\left(1-\mu_{P_{\mathrm{me}}}\right)^{\varphi_{e}}, \prod_{e=1}^{k}\left(v_{P_{\mathrm{me}}}\right)^{\varphi_{e}}, \prod_{e=1}^{k}\left(1-\mu_{P_{\mathrm{me}}}\right)^{w_{d}}\right.} \\
& \left.-\prod_{e=1}^{k}\left(1-\vartheta_{P_{\mathrm{me}}}\right)^{\varphi_{e}}\right]
\end{aligned}
$$

where $\hat{P}_{m}=\left(\mu_{\hat{P_{m}}}, \vartheta_{\hat{P}_{m}}, \pi_{\hat{P_{m}}}\right)$.

By using Table 3, the linguistic assessments for the alternatives are realized.

Step 3. Define the IF ideal solutions.

An IF has a positive ideal solution (IFPIS) and a negative ideal solution (IFNIS), which take values $\tau^{+}=$ $(1,0,0)$ and $\tau^{-}=(0,1,0)$, respectively. Whereas IFNIS 
Table 3 Linguistic phrases for a rating of alternatives [73]

\begin{tabular}{lc}
\hline Phrase & IFNs $[\mu, v]$ \\
\hline Extremely good (EG) & {$[1.00,0.00]$} \\
Very very good (VVG) & {$[0.85,0.10]$} \\
Very good (VG) & {$[0.80,0.15]$} \\
Good (G) & {$[0.70,0.20]$} \\
Medium good (MG) & {$[0.60,0.30]$} \\
Fair (F) & {$[0.50,0.40]$} \\
Medium bad (MB) & {$[0.40,0.50]$} \\
Bad (B) & {$[0.25,0.60]$} \\
Very bad (VB) & {$[0.10,0.75]$} \\
Very very bad (VVB) & {$[0.10,0.90]$} \\
\hline
\end{tabular}

and IFPIS are characterized by max and min operators, it is noted that there is no significant gap in their outcomes [8].

Step 4. Calculate the distance measures.

To compute the distance measure, a fuzzy normalized Euclidean distance equation is applied [80]. $\delta_{m}^{+}$and $\delta_{m}^{-}$are handled in Eqs. (4)-(5) to illustrate positive and negative distance measures, respectively.

$\delta_{m}^{+}=\sqrt{\left(\mu_{\widehat{P}_{m}}-\tau^{+}\right)^{2}+\left(\vartheta_{\widehat{P}_{m}}-\tau^{+}\right)^{2}+\left(\pi{\widehat{P_{m}}}-\tau^{+}\right)^{2}}$

$\delta_{m}^{-}=\sqrt{\left(\mu_{\widehat{P}_{m}}-\tau^{-}\right)^{2}+\left(\vartheta_{\widehat{P}_{m}}-\tau^{-}\right)^{2}+\left(\pi_{\widehat{P}_{m}}-\tau^{-}\right)^{2}}$

Step 5. Determine the closeness coefficient (CC) values and calculate the criteria weights.

As $\mathrm{CW}_{m}$ is the $\mathrm{CC}$ of the $m$ th criterion, it is computed by using Eq. (6).

$\mathrm{CW}_{m}=\frac{\delta_{m}^{-}}{\delta_{m}^{-}+\delta_{m}^{+}}$

After the whole CC values are computed, the criteria weights could be found by normalization.

Step 6. Establish the initial IF decision matrix.

It is the matrix of CC values obtained in Step 5. This matrix also specifies the type of optimization (benefit or cost) of each criterion.

Step 7. Construct the normalized IF decision matrix.

Evaluation criteria are normalized by using the linear max-min normalization approach. To do so, Eq. (7) is used for benefit-based criteria, while Eq. (8) is applied for costbased criteria.

$\begin{array}{ll}n_{i j}=\frac{x_{i j}-x_{\min }}{x_{\max }-x_{\min }} & \text { if } x_{i j} \in B \\ n_{i j}=\frac{x_{\max }-x_{i j}}{x_{\max }-x_{\min }} & \text { if } x_{i j} \in C\end{array}$

Step 8. Determine the theoretical IF decision matrix.
Via Eq. (9), first, the preference for any of the $f$ possible alternatives is decided.

$P_{A_{i}}=\frac{1}{f}$

where $\sum_{i=1}^{f} P_{A_{i}}=1$.

Thereafter, preferences for the selection of alternatives are multiplied with criteria weights, thus the theoretical IF matrix $\left(T_{p}\right)$ is derived (Eq. 10).

$T_{p}=P_{A_{i}} \cdot\left[t_{p 1} t_{p 2} \ldots t_{p n}\right]$

where $n$ is the total number of criteria and $t_{p i}$ is the theoretical rating.

Step 9. Establish the real IF evaluation matrix.

To form the real IF evaluation matrix, the elements of the normalized IF decision matrix are multiplied by the elements of the theoretical IF decision matrix (Eq. (11)).

$r_{i j}=n_{i j} \cdot t_{p i}$

Step 10. Build the IF gap matrix.

By using Eq. (12), the IF gap matrix is gathered by subtracting the real IF evaluation matrix from the theoretical IF decision matrix.

$g_{i j}=t_{p i}-r_{i j}$

Step 11. Calculate the utility scores of alternatives.

The utility scores of alternatives can be found by summing the elements of the IF gap matrix by rows, Eq. (13).

$q_{i j}=\sum_{j=1}^{n} g_{i j}, i=1,2, \ldots, f$

where $n$ is the total number of criteria and $f$ is the total number of the alternatives.

Step 12. Rank the alternatives and choose the finest one.

Once all utility scores are calculated, finally, alternatives are ranked from smallest to largest according to their utility scores. It should be stated that the alternative with the smallest utility score is the best among the others since it is very close to the theoretically best positioning alternative.

\section{The IF-MAIRCA framework for coronavirus vaccine selection}

In this research, an IF-MAIRCA framework for aiding to determine the best coronavirus vaccine is introduced, as depicted in Fig. 1.

The decision-makers committee consists of four experts with doctorate degrees in medicine from infectious diseases $(E 1)$, internal medicine (E2), virology (E3), and chest diseases (E4). The experts who have sufficient knowledge about coronavirus vaccines have working experience of no 


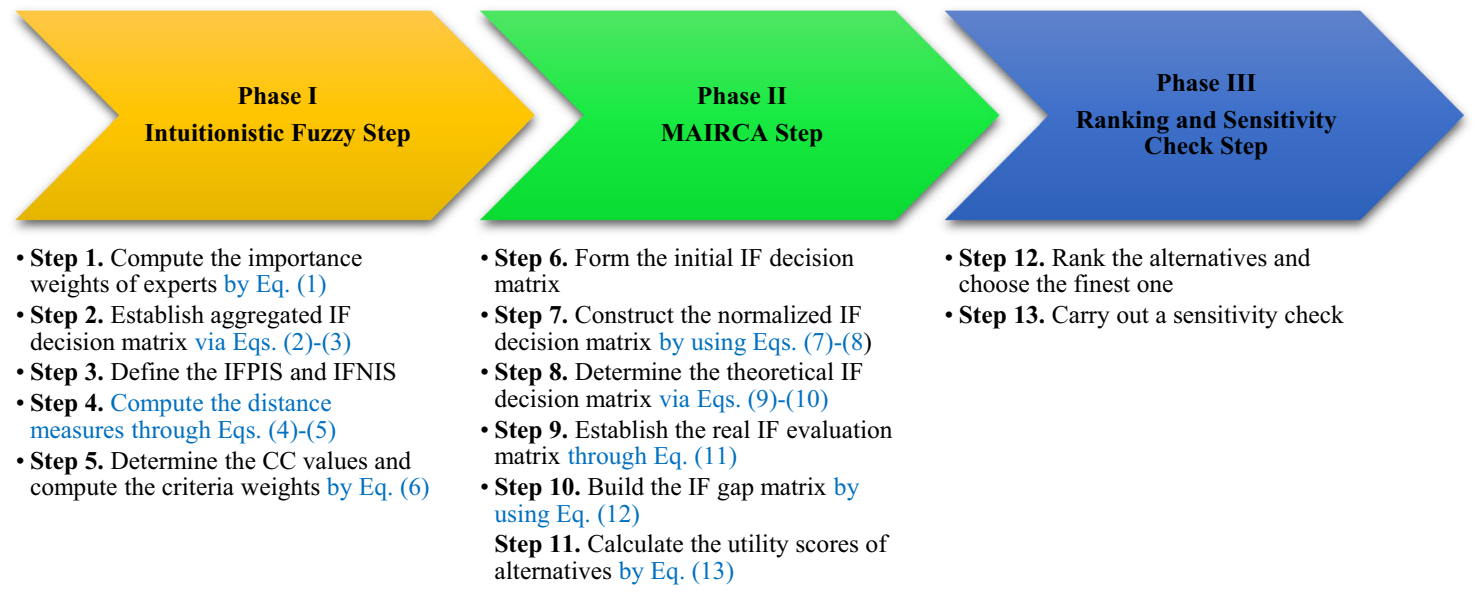

Fig. 1 Flow diagram of the introduced coronavirus vaccine selection framework

less than eighteen years and work still in various universities in Turkey.

In the study, five coronavirus vaccines approved by the EMA, FDA, and WHO are included for analysis. That is, Comirnaty (A1), mRNA-1273 (A2), AZD1222 (A3), CoronaVac (A4), and Sputnik V (A5) are taken as alternatives into account. Detailed information about the alternatives is given in Appendix A.

Furthermore, the following eight quantitative and qualitative criteria are determined for the analysis based on both the knowledge of experts. Hundred percent ambiguities are accepted to data to which uncertainty information is not ensured [60]. To better define these criteria, this research addresses linguistic terms, which are closer to human thinking than exact numbers.

\subsection{Duration of protection (C1)}

It refers to the duration in which vaccinated people are expected to become immune to coronavirus. After receiving the second dose of vaccine for all coronavirus vaccines, meanwhile, the protection begins 2-3 weeks later. Experts are still trying to learn how long vaccines are protective in real life. However, clinical trials conducted by vaccine manufacturers give some clues about the protection period of the vaccines. For example, in people who received two doses of the mRNA-1273 vaccine, it was reported that the high level of protection of the vaccine was increased for up to 6 months [12].

\subsection{Success against the mutations (C2)}

It refers to the vaccine's ability to protect against different genetic variants of the coronavirus. Recently, it has been observed that the coronavirus has changed in different countries like England, South Africa, Brazil, and Finland and different variants have emerged. Such variants make people worry and, as a result, the reliability of vaccines developed is questioned. A variant remains susceptible to one potential mechanism of vaccine-mediated protection but cannot escape from that protection [50]. Very recently, Liu et al. [50] proved that the Comirnaty vaccine is also effective against recombinant (mutant) viruses.

\subsection{Storage conditions (C3)}

It means to the conditions such as temperature and storage environment necessary for the vaccines to not lose their unique properties. Storage conditions for vaccines are a significant factor because disadvantageous storage conditions are a barrier to the distribution of vaccines to the rest of the world. From this point of view, conventional vaccines (AZD1222, Sputnik V, and CoronaVac) offer storage advantages [43].

\subsection{Effectiveness of the vaccine (C4)}

It refers to the success in preventing death and serious illness. Effectiveness is a vital parameter for vaccines [43]. It is claimed that the effectiveness of the current vaccines in preventing serious illness and death is close to 100 percent. Khurana et al. [43] stated that the primary data revealed Comirnaty and mRNA-1273 have an efficacy of 95\% and $94.5 \%$ against COVID-19, respectively. However, it has been noted that the effectiveness in preventing disease development in the vaccinated person differs from vaccine to vaccine.

\subsection{Logistics (C5)}

It refers to the ease or difficulty experienced in transporting vaccines. For instance, Pfizer has developed its own 
packaging that allows the doses to be preserved for 10 days without special freezers, but the doses still need to be flown from Belgium and then sent to vaccination centers in trucks with thermosensors and GPS trackers. This situation constitutes one of the biggest obstacles to its distribution to poor countries that do not have the necessary technological infrastructure. On the other hand, traditional vaccines have important superiorities like easy shipping [72].

\subsection{Number of vaccine doses (C6)}

It expresses the number of vaccine doses required for the vaccine to be effective against coronavirus. The current coronavirus vaccines are usually received in two doses with a time interval of a few weeks to ensure adequate immunity in the body [58]. The reason for this is to increase the amount of antibody, which decreased after receiving the first dose, to a certain level with the second dose. According to Bouazzaoui et al. [18], one of the most significant disadvantages of conventional vaccines is the need for multiple doses to achieve immunity.

\subsection{Price (C8)}

It refers to the price of one dose of coronavirus vaccine. It can be stated that another difference between available coronavirus vaccines is their price [43]. At present, the AZD1222 vaccine attracts attention as the cheapest vaccine (only \$6/per dose). Prices per dose for Comirnaty, mRNA1273 , CoronaVac, and Sputnik V vaccines are \$37, \$39, $\$ 60$, and $\$ 20$, respectively [25]. Thus, the low price of mRNA vaccines is seen as an important advantage [18].

In sum, an evaluation system for the coronavirus vaccine selection is presented in Fig. 2. The solution stages of the introduced framework are clarified in detail below.

Step 1. As the proposed IF-MAIRCA model is a group decision-based model, at first, the importance weights of decision-makers are determined via Eq. (1). The importance weights of experts are presented in Table 4.

For instance, the importance weight of $E l$ is computed as follows:

$$
\varphi_{E_{1}}=\frac{0.88+0.04\left(\frac{0.88}{0.88+0.08}\right)}{0.88+0.04\left(\frac{0.88}{0.88+0.08}\right)+0.75+0.05\left(\frac{0.75}{0.75+0.2}\right)+0.88+0.04\left(\frac{0.88}{0.88+0.08}\right)+0.75+0.05\left(\frac{0.75}{0.75+0.2}\right)}=0.269
$$

\subsection{Side effects (C7)}

It depicts undesirable conditions such as headache, fever, and fatigue that occur after vaccination. According to Deutsche [25], since the introduction of the Comirnaty vaccine, some people have been shown to have allergic reactions immediately after vaccination. In the mRNA1273 , allergic reactions were observed in very few of the volunteers who were administered the vaccine, while exhaustion was observed in 9.7 percent. So far, there has been no report of serious side effects of the Sputnik V vaccine. However, complaints such as headache and fever, which are considered as usual side effects, were reported. According to CoronaVac volunteers, mild side effects occurred and these side effects disappeared within two days. It was stated that the most important side effect was a pain in the area where the vaccine was given. On the other hand, Oldenburg et al. [58] highlighted that 13 cases of thrombosis with more than 1.6 million AZD1222 vaccine doses administered.
Step 2. The linguistic assessments of eight criteria are carried out by the experts by helping of Table 2, which evaluate the five coronavirus vaccine options according to the eight attributes utilizing Table 3. The linguistic expressions for the evaluation criteria and options are given in Tables 5 and 6, respectively.

By using Eqs. (2) and (3), the aggregated IF decision matrix shown in Table 7 is established. For example, aggregated $\mu, \vartheta$, and $\pi$ of $C l$ could be found as follows:

$$
\begin{aligned}
& \mu=1-\left((1-0.88)^{0.269} \times(1-0.88)^{0.231}\right. \\
& \left.\times(1-0.88)^{0.269} \times(1-0.88)^{0.231}\right)=0.88 \\
& \vartheta=0.08^{0.269} \times 0.08^{0.231} \times 0.08^{0.269} \times 0.08^{0.231}=0.08 \\
& \pi=1-(0.88+0.08)=0.04
\end{aligned}
$$

Step 3. In this step, as mentioned above, the IFPIS and IFNIS are $\tau^{+}=(1,0,0)$ and $\tau^{-}=(0,1,0)$, respectively.

Step 4. Compute the distance measures.

Taking Table 7 into consideration, $\delta_{m}^{+}, \delta_{m}^{-}$, and the IF weights of each criterion are calculated by using Eqs. (4)- 
Fig. 2 An assessment system for coronavirus vaccine selection

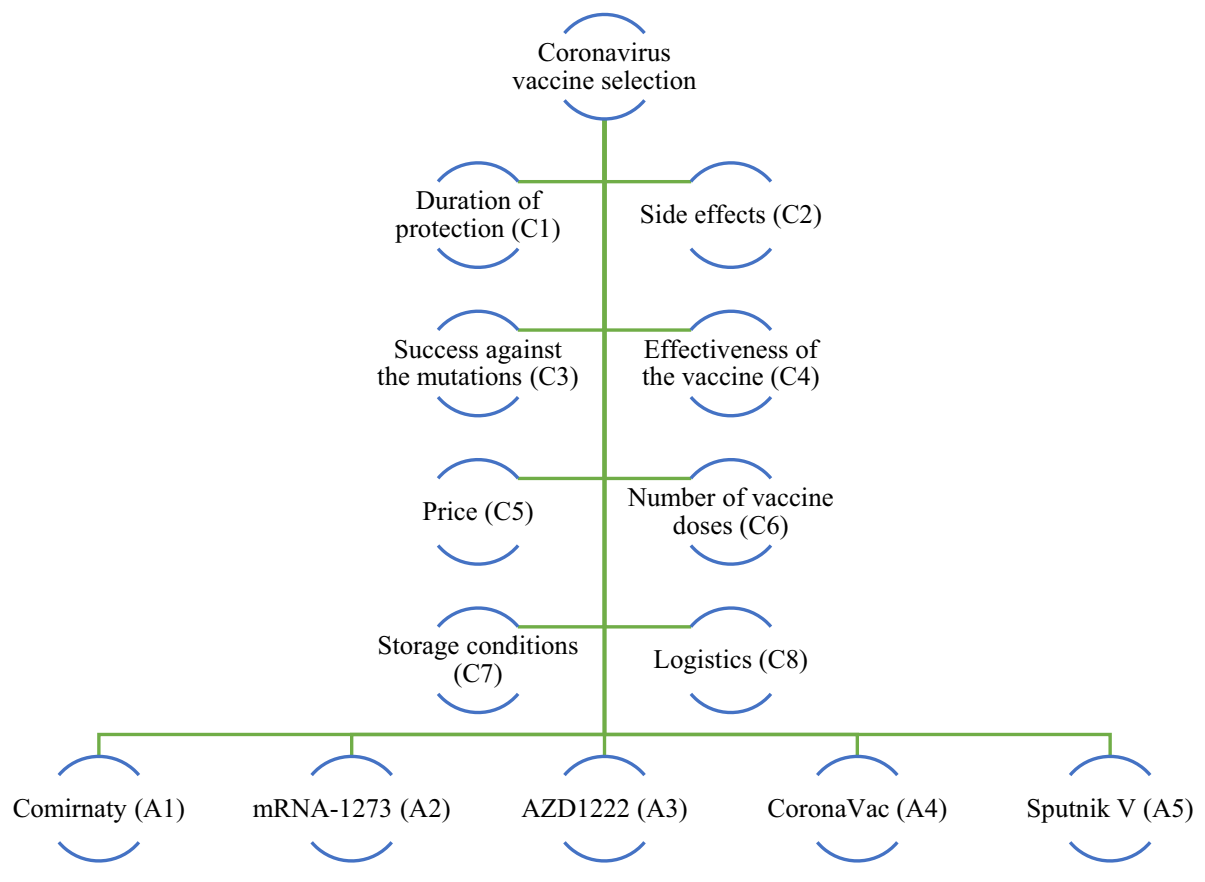

Table 4 The importance weights of experts

\begin{tabular}{lllll}
\hline & $E 1$ & $E 2$ & $E 3$ & E4 \\
\hline Linguistic phrase & VI & I & VI & I \\
Weight & 0.269 & 0.231 & 0.269 & 0.231 \\
\hline
\end{tabular}

(5) as presented in Table 8. For example, $\delta_{1}^{+}$and $\delta_{1}^{-}$for $C 1$ are calculated as follows:

$\delta_{1}^{+}=\sqrt{(0.88-1)^{2}+(0.08-0)^{2}+(0.04-0)^{2}}=0.15$

$\delta_{1}^{-}=\sqrt{(0.88-0)^{2}+(0.08-1)^{2}+(0.04-0)^{2}}=1.274$
Step 5. Determine the CC values and compute the criteria weights.

$\mathrm{CC}$ values of criteria are calculated by Eq. (6). For instance, the $\mathrm{CC}$ value of $\mathrm{Cl}$ is found as follows:

$\mathrm{CW}_{1}=\frac{1.274}{1.274+0.15}=0.895$

Based on the obtained CC values shown in Table 9, thereafter, normalization is performed and the criteria weights are determined.

Thereby, $C l$ is specified as the most significant criterion.

Step 6. Form the initial IF decision matrix.

To determine elements of the IF decision matrix, firstly, the values $\mu, \vartheta$, and $\pi$ are computed in this stage based on Tables 6, 10 .

Thereafter, through Table 10 and Eqs. (4)-(6), Table 11 is obtained.

Table 5 Linguistic evaluations of criteria by experts

\begin{tabular}{lllll}
\hline Criteria & Experts & & & \\
\cline { 2 - 5 } & E1 & E2 & E3 & VI \\
\hline$C 1$ & $\mathrm{VI}$ & $\mathrm{VI}$ & $\mathrm{I}$ & $\mathrm{VI}$ \\
$C 2$ & $\mathrm{VI}$ & $\mathrm{I}$ & $\mathrm{VI}$ & $\mathrm{VI}$ \\
$C 3$ & $\mathrm{I}$ & $\mathrm{M}$ & $\mathrm{VI}$ & $\mathrm{I}$ \\
$C 4$ & $\mathrm{VI}$ & $\mathrm{I}$ & $\mathrm{I}$ & $\mathrm{I}$ \\
$C 5$ & $\mathrm{VI}$ & $\mathrm{I}$ & $\mathrm{I}$ & $\mathrm{MI}$ \\
$C 6$ & $\mathrm{M}$ & $\mathrm{M}$ & $\mathrm{I}$ & $\mathrm{M}$ \\
$C 7$ & $\mathrm{I}$ & $\mathrm{M}$ & $\mathrm{I}$ & $\mathrm{I}$ \\
$C 8$ & $\mathrm{M}$ & $\mathrm{I}$ & $\mathrm{I}$ \\
\hline
\end{tabular}


Table 6 Linguistic evaluations of alternatives by experts

\begin{tabular}{|c|c|c|c|c|c|c|c|c|c|}
\hline \multirow[t]{2}{*}{ Alternatives } & \multirow[t]{2}{*}{ Experts } & \multicolumn{8}{|c|}{ Criteria } \\
\hline & & $C 1$ & $C 2$ & $C 3$ & $C 4$ & $C 5$ & C6 & $C 7$ & $C 8$ \\
\hline \multirow[t]{4}{*}{$A 1$} & E1 & EG & MG & VB & EG & $\mathrm{F}$ & G & B & $\mathrm{F}$ \\
\hline & $E 2$ & VVG & MG & B & EG & $\mathrm{F}$ & MG & B & $\mathrm{F}$ \\
\hline & E3 & EG & MG & B & EG & MG & G & $\mathrm{MB}$ & $\mathrm{F}$ \\
\hline & $E 4$ & VVG & $\mathrm{F}$ & VVB & VVG & MG & G & MB & MG \\
\hline \multirow[t]{4}{*}{$A 2$} & E1 & VVG & $\mathrm{F}$ & B & VVG & G & MG & $\mathrm{MB}$ & VG \\
\hline & $E 2$ & EG & $\mathrm{F}$ & $\mathrm{MB}$ & VVG & G & G & B & VG \\
\hline & E3 & EG & MG & $\mathrm{MB}$ & VVG & MG & G & $\mathrm{MB}$ & G \\
\hline & $E 4$ & EG & MG & $\mathrm{MB}$ & EG & MG & G & $\mathrm{MB}$ & G \\
\hline \multirow{4}{*}{$A 3$} & E1 & EG & G & VVG & VG & EG & G & VVG & VVG \\
\hline & $E 2$ & VVG & G & EG & $\mathrm{G}$ & EG & $\mathrm{G}$ & VVG & VVG \\
\hline & E3 & VVG & G & VG & G & EG & MG & EG & VVG \\
\hline & $E 4$ & EG & MG & VG & G & EG & $\mathrm{G}$ & EG & VVG \\
\hline \multirow[t]{4}{*}{$A 4$} & E1 & VG & VVG & EG & G & G & $\mathrm{G}$ & EG & $\mathrm{G}$ \\
\hline & $E 2$ & G & VVG & EG & G & G & G & EG & G \\
\hline & E3 & $\mathrm{G}$ & $\mathrm{G}$ & EG & G & VG & $\mathrm{G}$ & EG & VG \\
\hline & $E 4$ & VG & VVG & VVG & $\mathrm{G}$ & $\mathrm{G}$ & MG & VVG & $\mathrm{VG}$ \\
\hline \multirow[t]{4}{*}{$A 5$} & E1 & VG & G & VVG & EG & VVG & G & EG & EG \\
\hline & $E 2$ & $\mathrm{VG}$ & $\mathrm{G}$ & VVG & VVG & EG & MG & EG & VVG \\
\hline & $E 3$ & $\mathrm{G}$ & VVG & $\mathrm{G}$ & VVG & VVG & $\mathrm{G}$ & VVG & VVG \\
\hline & E4 & $\mathrm{G}$ & VVG & $\mathrm{G}$ & VVG & VG & G & VVG & VVG \\
\hline
\end{tabular}

Table 7 The aggregated IF decision matrix

\begin{tabular}{llll}
\hline & $\mu$ & $\vartheta$ & $\pi$ \\
\hline$C 1$ & 0.880 & 0.080 & 0.040 \\
$C 2$ & 0.827 & 0.126 & 0.047 \\
$C 3$ & 0.759 & 0.189 & 0.052 \\
$C 4$ & 0.858 & 0.099 & 0.043 \\
$C 5$ & 0.827 & 0.126 & 0.047 \\
$C 6$ & 0.585 & 0.362 & 0.053 \\
$C 7$ & 0.752 & 0.195 & 0.052 \\
$C 8$ & 0.637 & 0.309 & 0.054 \\
\hline
\end{tabular}

Table 8 The $\delta_{1}^{+}$and $\delta_{1}^{-}$values of the criteria

\begin{tabular}{lll}
\hline & $\delta_{m}^{+}$ & $\delta_{m}^{-}$ \\
\hline$C 1$ & 0.150 & 1.274 \\
$C 2$ & 0.220 & 1.204 \\
$C 3$ & 0.310 & 1.112 \\
$C 4$ & 0.179 & 1.245 \\
$C 5$ & 0.220 & 1.204 \\
$C 6$ & 0.553 & 0.867 \\
$C 7$ & 0.320 & 1.103 \\
$C 8$ & 0.480 & 0.941 \\
\hline
\end{tabular}

Table $9 \mathrm{CC}$ values and weights of evaluation criteria

\begin{tabular}{lll}
\hline & CC & Weight \\
\hline$C 1$ & 0.895 & 0.1422 \\
$C 2$ & 0.846 & 0.1344 \\
$C 3$ & 0.782 & 0.1243 \\
$C 4$ & 0.875 & 0.1390 \\
$C 5$ & 0.846 & 0.1344 \\
$C 6$ & 0.611 & 0.0970 \\
$C 7$ & 0.775 & 0.1232 \\
$C 8$ & 0.662 & 0.1053 \\
Total & 6.291 & \\
\hline
\end{tabular}

Last but not least, the initial IF decision matrix can be built as shown in Table 12 .

Step 7. Construct the normalized IF decision matrix.

By both utilizing Eqs. (7)-(8) and Table 12, elements of the normalized IF decision matrix are identified (Table 13).

For instance, the normalized value of $C l$ (as a benefittype criterion) subject to $A l$ is found as follows: 
Table 10 Aggregated $\mu, \vartheta$, and $\pi$ values of alternatives subject to each criterion

Table 11 Aggregated IF decision matrix for alternatives

\begin{tabular}{|c|c|c|c|c|c|c|c|c|c|c|c|c|}
\hline & \multicolumn{3}{|l|}{$C 1$} & \multicolumn{3}{|l|}{$C 2$} & \multicolumn{3}{|l|}{$C 3$} & \multicolumn{3}{|l|}{$C 4$} \\
\hline & $\mu$ & $\vartheta$ & $\pi$ & $\mu$ & $\vartheta$ & $\pi$ & $\mu$ & $\vartheta$ & $\pi$ & $\mu$ & $\vartheta$ & $\pi$ \\
\hline$A 1$ & 1.000 & 0.000 & 0.000 & 0.579 & 0.321 & 0.101 & 0.178 & 0.700 & 0.122 & 1.000 & 0.000 & 0.000 \\
\hline$A 2$ & 1.000 & 0.000 & 0.000 & 0.553 & 0.346 & 0.101 & 0.363 & 0.525 & 0.112 & 1.000 & 0.000 & 0.000 \\
\hline$A 3$ & 1.000 & 0.000 & 0.000 & 0.679 & 0.220 & 0.101 & 1.000 & 0.000 & 0.000 & 0.731 & 0.185 & 0.084 \\
\hline$A 4$ & 0.755 & 0.173 & 0.072 & 0.819 & 0.120 & 0.060 & 1.000 & 0.000 & 0.000 & 0.700 & 0.200 & 0.100 \\
\hline \multirow[t]{3}{*}{$A 5$} & 0.755 & 0.173 & 0.072 & 0.788 & 0.141 & 0.071 & 0.788 & 0.141 & 0.071 & 1.000 & 0.000 & 0.000 \\
\hline & \multicolumn{3}{|l|}{$C 5$} & \multicolumn{3}{|l|}{ C6 } & \multicolumn{3}{|l|}{$C 7$} & \multicolumn{3}{|l|}{$C 8$} \\
\hline & $\mu$ & $\vartheta$ & $\pi$ & $\mu$ & $\vartheta$ & $\pi$ & $\mu$ & $\vartheta$ & $\pi$ & $\mu$ & $\vartheta$ & $\pi$ \\
\hline$A 1$ & 0.553 & 0.346 & 0.101 & 0.679 & 0.220 & 0.101 & 0.329 & 0.548 & 0.123 & 0.525 & 0.374 & 0.101 \\
\hline$A 2$ & 0.654 & 0.245 & 0.101 & 0.676 & 0.223 & 0.101 & 0.368 & 0.522 & 0.110 & 0.755 & 0.173 & 0.072 \\
\hline$A 3$ & 1.000 & 0.000 & 0.000 & 0.676 & 0.223 & 0.101 & 1.000 & 0.000 & 0.000 & 0.850 & 0.100 & 0.050 \\
\hline$A 4$ & 0.731 & 0.185 & 0.084 & 0.679 & 0.220 & 0.101 & 1.000 & 0.000 & 0.000 & 0.755 & 0.173 & 0.072 \\
\hline$A 5$ & 1.000 & 0.000 & 0.000 & 0.679 & 0.220 & 0.100 & 1.000 & 0.000 & 0.000 & 1.000 & 0.000 & 0.000 \\
\hline
\end{tabular}

\begin{tabular}{|c|c|c|c|c|c|c|c|c|c|c|c|c|}
\hline & \multicolumn{3}{|l|}{$C 1$} & \multicolumn{3}{|l|}{$C 2$} & \multicolumn{3}{|l|}{ C3 } & \multicolumn{3}{|l|}{ C4 } \\
\hline & $\delta_{m}^{+}$ & $\delta_{m}^{-}$ & $\mathrm{CW}$ & $\delta_{m}^{+}$ & $\delta_{m}^{-}$ & $\mathrm{CW}$ & $\delta_{m}^{+}$ & $\delta_{m}^{-}$ & $\mathrm{CW}$ & $\delta_{m}^{+}$ & $\delta_{m}^{-}$ & $\mathrm{CW}$ \\
\hline$A 1$ & 0.000 & 1.414 & 1.000 & 0.539 & 0.898 & 0.625 & 1.086 & 0.370 & 0.254 & 0.000 & 1.414 & 1.000 \\
\hline$A 2$ & 0.000 & 1.414 & 1.000 & 0.575 & 0.862 & 0.600 & 0.833 & 0.608 & 0.422 & 0.000 & 1.414 & 1.000 \\
\hline$A 3$ & 0.000 & 1.414 & 1.000 & 0.402 & 1.040 & 0.721 & 0.000 & 1.414 & 1.000 & 0.337 & 1.098 & 0.765 \\
\hline$A 4$ & 0.308 & 1.122 & 0.784 & 0.225 & 1.204 & 0.842 & 0.000 & 1.414 & 1.000 & 0.374 & 1.068 & 0.741 \\
\hline \multirow[t]{3}{*}{$A 5$} & 0.308 & 1.122 & 0.784 & 0.265 & 1.167 & 0.815 & 0.265 & 1.167 & 0.815 & 0.000 & 1.414 & 1.000 \\
\hline & \multicolumn{3}{|l|}{ C5 } & \multicolumn{3}{|l|}{ C6 } & \multicolumn{3}{|l|}{$C 7$} & \multicolumn{3}{|l|}{$C 8$} \\
\hline & $\delta_{m}^{+}$ & $\delta_{m}^{-}$ & $\mathrm{CW}$ & $\delta_{m}^{+}$ & $\delta_{m}^{-}$ & $\mathrm{CW}$ & $\delta_{m}^{+}$ & $\delta_{m}^{-}$ & $\mathrm{CW}$ & $\delta_{m}^{+}$ & $\delta_{m}^{-}$ & $\mathrm{CW}$ \\
\hline$A 1$ & 0.575 & 0.862 & 0.600 & 0.402 & 1.040 & 0.721 & 0.875 & 0.573 & 0.396 & 0.613 & 0.823 & 0.573 \\
\hline$A 2$ & 0.436 & 1.004 & 0.697 & 0.406 & 1.035 & 0.718 & 0.827 & 0.614 & 0.426 & 0.308 & 1.122 & 0.784 \\
\hline$A 3$ & 0.000 & 1.414 & 1.000 & 0.406 & 1.035 & 0.718 & 0.000 & 1.414 & 1.000 & 0.187 & 1.239 & 0.869 \\
\hline A4 & 0.337 & 1.098 & 0.765 & 0.402 & 1.040 & 0.721 & 0.000 & 1.414 & 1.000 & 0.308 & 1.122 & 0.784 \\
\hline$A 5$ & 0.000 & 1.414 & 1.000 & 0.401 & 1.039 & 0.721 & 0.000 & 1.414 & 1.000 & 0.000 & 1.414 & 1.000 \\
\hline
\end{tabular}

Table 12 The initial IF decision matrix

\begin{tabular}{llllllllr}
\hline & $C 1$ & $C 2$ & $C 3$ & $C 4$ & $C 5$ & C6 & C7 \\
\hline $\begin{array}{l}\text { Optimization } \\
\text { Alternatives }\end{array}$ & Max & Max & Max & Max & Max & Min & Min & Min \\
A1 & & & & & & & \\
A2 & 1.0000 & 0.6250 & 0.2541 & 1.0000 & 0.6000 & 0.7213 & 0.3957 & 0.5732 \\
$A 3$ & 1.0000 & 0.6000 & 0.4219 & 1.0000 & 0.6971 & 0.7181 & 0.4261 & 0.7844 \\
$A 4$ & 1.0000 & 0.7213 & 1.0000 & 0.7650 & 1.0000 & 0.7181 & 1.0000 & 0.8688 \\
A5 & 0.7844 & 0.8423 & 1.0000 & 0.7405 & 0.7650 & 0.7213 & 1.0000 & 0.7844 \\
Max & 0.7844 & 0.8152 & 0.8152 & 1.0000 & 1.0000 & 0.7214 & 1.0000 & 1.0000 \\
Min & 1.0000 & 0.8423 & 1.0000 & 1.0000 & 1.0000 & 0.7214 & 1.0000 & 1.0000 \\
\hline
\end{tabular}


Table 13 The normalized IF decision matrix

\begin{tabular}{lllllllll}
\hline & $C 1$ & $C 2$ & $C 3$ & $C 4$ & $C 5$ & $C 6$ & $C 7$ & 1.0000 \\
\hline$A 1$ & 1.0000 & 0.1033 & 0.0000 & 1.0000 & 0.0000 & 0.0312 & 1.0000 \\
$A 2$ & 1.0000 & 0.0000 & 0.2250 & 1.0000 & 0.2426 & 1.0000 & 0.9497 & 0.5052 \\
$A 3$ & 1.0000 & 0.5008 & 1.0000 & 0.0946 & 1.0000 & 1.0000 & 0.0000 & 0.3074 \\
$A 4$ & 0.0000 & 1.0000 & 1.0000 & 0.0000 & 0.4126 & 0.0312 & 0.0000 & 0.5052 \\
$A 5$ & 0.0000 & 0.8884 & 0.7523 & 1.0000 & 1.0000 & 0.0000 & 0.0000 & 0.0000 \\
\hline
\end{tabular}

Table 14 The theoretical IF decision matrix

\begin{tabular}{lllllllll}
\hline & $C 1$ & $C 2$ & $C 3$ & $C 4$ & $C 5$ & $C 6$ & $C 7$ & 0.0246 \\
$A 1$ & 0.0284 & 0.0269 & 0.0249 & 0.0278 & 0.0269 & 0.0194 & 0.0211 \\
$A 2$ & 0.0284 & 0.0269 & 0.0249 & 0.0278 & 0.0269 & 0.0194 & 0.0246 \\
$A 3$ & 0.0284 & 0.0269 & 0.0249 & 0.0278 & 0.0269 & 0.0194 & 0.0246 & 0.0211 \\
$A 4$ & 0.0284 & 0.0269 & 0.0249 & 0.0278 & 0.0269 & 0.0194 & 0.0246 & 0.0211 \\
$A 5$ & 0.0284 & 0.0269 & 0.0249 & 0.0278 & 0.0269 & 0.0194 & 0.0246 & 0.0211 \\
\hline
\end{tabular}

Table15 The real IF evaluation matrix

\begin{tabular}{lllllllll}
\hline & $C 1$ & $C 2$ & $C 3$ & $C 4$ & $C 5$ & $C 6$ & $C 7$ & 0.0211 \\
\hline$A 1$ & 0.0284 & 0.0028 & 0.0000 & 0.0278 & 0.0000 & 0.0006 & 0.0246 \\
$A 2$ & 0.0284 & 0.0000 & 0.0056 & 0.0278 & 0.0065 & 0.0194 & 0.0234 \\
$A 3$ & 0.0284 & 0.0135 & 0.0249 & 0.0026 & 0.0269 & 0.0194 & 0.0000 & 0.0106 \\
$A 4$ & 0.0000 & 0.0269 & 0.0249 & 0.0000 & 0.0111 & 0.0006 & 0.0000 & 0.0106 \\
$A 5$ & 0.0000 & 0.0239 & 0.0187 & 0.0278 & 0.0269 & 0.0000 & 0.0000 & 0.0000 \\
\hline
\end{tabular}

Table 16 The IF gap matrix

\begin{tabular}{lllllllll}
\hline & $C 1$ & $C 2$ & $C 3$ & $C 4$ & $C 5$ & $C 6$ & $C 7$ \\
\hline$A 1$ & 0.0000 & 0.0241 & 0.0249 & 0.0000 & 0.0269 & 0.0188 & 0.0000 & 0.0000 \\
$A 2$ & 0.0000 & 0.0269 & 0.0193 & 0.0000 & 0.0204 & 0.0000 & 0.0012 & 0.0104 \\
$A 3$ & 0.0000 & 0.0134 & 0.0000 & 0.0252 & 0.0000 & 0.0000 & 0.0246 & 0.0146 \\
$A 4$ & 0.0284 & 0.0000 & 0.0000 & 0.0278 & 0.0158 & 0.0188 & 0.0246 & 0.0104 \\
$A 5$ & 0.0284 & 0.0030 & 0.0062 & 0.0000 & 0.0000 & 0.0194 & 0.0246 & 0.0211 \\
\hline
\end{tabular}

$n_{11}=\frac{1-0.7844}{1-0.7844}=1$

On the other hand, the normalized value of $C 6$ (as a cost-type criterion) as per $A l$ is determined as follows:

$n_{16}=\frac{0.7214-0.7213}{0.7214-0.7181}=0.031$
Step 8. Determine the theoretical IF decision matrix.

As pointed out previously, by using Eq. (10), the theoretical IF decision matrix (Table 14) is identified by multiplying preferences for the selection of alternatives and criteria weights. Since the case study in this work is made according to the evaluation of five alternatives, via Eq. (9), 
Table 17 The utility scores and rank orders

\begin{tabular}{lll}
\hline Alternative & Utility score & Rank \\
\hline$A 1$ & 0.0947 & 3 \\
A2 & 0.0782 & 2 \\
A3 & 0.0778 & 1 \\
A4 & 0.1259 & 5 \\
A5 & 0.1027 & 4 \\
\hline
\end{tabular}

the preference for the selection of alternatives is 0.2 (1/ $5=0.2$ ).

Subject to $C l$, for instance, the theoretical value of $A l$ is:

$P_{A_{i}} \cdot t_{p 1}=0.1422 \times 0.2=0.0284$

Step 9. Establish the real IF evaluation matrix.

Via Eq. (11), it is obtained the real IF evaluation matrix as presented in Table 15.

According to $C l$, the real value of $A l$ is:

$r_{11}=1 \times 0.0284=0.0284$

Step 10. Build the IF gap matrix.

The IF gap matrix shown in Table 16 is constructed through Eq. (12).

For instance,

$g_{11}=0.0284-0.0284=0$.

Steps 11 and 12. Calculate the utility scores and the alternatives.

As presented in Table 17, by using Eq. (13), the utility scores of alternatives are calculated by summing the elements of the IF gap matrix by rows.

For instance, the utility score of $A l$ is found as follows:

$q_{1}=0+0.0241+0.0249+0+0.0269+0.0188+0+0$ $=0.0947$

Once alternatives are ranked in ascending order as per their benefit scores, the most preferred alternative is $A 3$. In a nutshell, AZD1222 is the best coronavirus vaccine among others with regard to the proposed framework.

\section{Comparison and sensitivity assessment}

The suitability of employing the proposed methodology for the goal of coronavirus vaccine selection could be shown by a detailed sensitivity check. The sensitivity check consists of four parts. First, the effect of the change of the most significant criterion $(\mathrm{Cl})$ on the ranking outcomes is examined. The modification of $w 1$ is made by 40 scenarios, whereas the weights of the rest are proportionally changed to satisfy the condition $\sum_{j=1}^{n} w_{j}=1$ simultaneously. Second, the effect of changes in the weight of experts on ranking outcomes is investigated. Third, it is the comparison of the rankings derived performing some IF extensions of MCDM methods. Last but not least, the effect of a change in linguistic assessments is discovered. The sensitivity check is performed in MS Excel.

\subsection{Changing the weight values of the criteria}

In this subsection, the effect of the change in the weight of the most significant criterion $\left(w_{1}\right)$ on the ranking outcomes is examined. Firstly, it is formed 40 new vectors of weight coefficients, which are categorized into 40 scenarios. The novel vectors of weight coefficients are created by reducing the weight coefficient $w_{1}$ by $1 \%$ in each scenario. So, the change of $w_{1}$ in the interval $w_{1} \in[0.0839,0.1408]$ is created, where $w_{1}=0.1408$ means the value of the weighting factor in Scenario $1(\mathrm{Sc} 1)$, while the value $w_{1}=0.0839$ means the value of the weighting factor in Scenario 40 (Sc40). After each modification of $w_{1}$, by performing Eq. 14, the weights of the rest criteria are obtained.

$\omega_{m \gamma}=\left(1-\omega_{m \pi}\right) \cdot \frac{\omega_{\gamma}}{\left(1-\omega_{m}\right)}$

where $m$ shows any criterion, $\omega_{m \gamma}$ shows the modified value of $m, \omega_{m \pi}$ shows the reduced value of the finest criterion $(C 1), \omega_{\gamma}$ shows the original value of $m$, and $\omega_{m}$ shows the original value of finest criterion $(C 1)$. For example, the calculations for the first scenario $(\mathrm{Sc} 1)$ are as follows. The Sc1 value of $C l$ becomes 0.1408 as a result of a $1 \%$ reduction of its real weight value of 0.1422 $(0.1422 \times 0.99=0.1408)$. Thereafter, by Eq. 14 , the weights of the remaining criteria are as follows:

$$
\begin{aligned}
& \omega_{2}=(1-0.1408) \cdot \frac{0.1344}{(1-0.1422)}=0.1347 \\
& \omega_{3}=(1-0.1408) \cdot \frac{0.1243}{(1-0.1422)}=0.1245 \\
& \omega_{4}=(1-0.1408) \cdot \frac{0.1390}{(1-0.1422)}=0.1392 \\
& \omega_{5}=(1-0.1408) \cdot \frac{0.1344}{(1-0.1422)}=0.1347 \\
& \omega_{6}=(1-0.1408) \cdot \frac{0.0970}{(1-0.1422)}=0.0972 \\
& \omega_{7}=(1-0.1408) \cdot \frac{0.1232}{(1-0.1422)}=0.1234 \\
& \omega_{8}=(1-0.1408) \cdot \frac{0.1053}{(1-0.1422)}=0.1055
\end{aligned}
$$


Table 18 New weight scenarios achieved with $1 \%$ reduction of $w_{1}$

\begin{tabular}{|c|c|c|c|c|c|c|c|c|c|c|}
\hline & \multicolumn{10}{|c|}{ Scenarios } \\
\hline & $\mathrm{Sc} 1$ & $\mathrm{Sc} 2$ & Sc3 & $\mathrm{Sc} 4$ & Sc5 & Sc6 & Sc7 & Sc8 & $\mathrm{Sc} 9$ & Sc10 \\
\hline$C 1$ & 0.1408 & 0.1394 & 0.1380 & 0.1366 & 0.1351 & 0.1337 & 0.1323 & 0.1309 & 0.1294 & 0.1280 \\
\hline$C 2$ & 0.1347 & 0.1349 & 0.1351 & 0.1353 & 0.1356 & 0.1358 & 0.1360 & 0.1362 & 0.1364 & 0.1367 \\
\hline$C 3$ & 0.1245 & 0.1247 & 0.1249 & 0.1251 & 0.1253 & 0.1255 & 0.1257 & 0.1259 & 0.1261 & 0.1263 \\
\hline$C 4$ & 0.1392 & 0.1395 & 0.1397 & 0.1399 & 0.1402 & 0.1404 & 0.1406 & 0.1409 & 0.1411 & 0.1413 \\
\hline$C 5$ & 0.1347 & 0.1349 & 0.1351 & 0.1353 & 0.1356 & 0.1358 & 0.1360 & 0.1362 & 0.1364 & 0.1367 \\
\hline C6 & 0.0972 & 0.0974 & 0.0975 & 0.0977 & 0.0979 & 0.0980 & 0.0982 & 0.0983 & 0.0985 & 0.0987 \\
\hline$C 7$ & 0.1234 & 0.1236 & 0.1239 & 0.1241 & 0.1243 & 0.1245 & 0.1247 & 0.1249 & 0.1251 & 0.1253 \\
\hline \multirow[t]{2}{*}{ C8 } & 0.1055 & 0.1056 & 0.1058 & 0.1060 & 0.1062 & 0.1063 & 0.1065 & 0.1067 & 0.1069 & 0.1070 \\
\hline & Sc11 & Sc12 & $\mathrm{Sc} 13$ & Sc14 & Sc15 & Sc16 & Sc17 & Sc18 & Sc19 & Sc20 \\
\hline$C 1$ & 0.1266 & 0.1252 & 0.1238 & 0.1223 & 0.1209 & 0.1195 & 0.1181 & 0.1166 & 0.1138 & 0.1124 \\
\hline$C 2$ & 0.1369 & 0.1371 & 0.1373 & 0.1376 & 0.1378 & 0.1380 & 0.1382 & 0.1385 & 0.1389 & 0.1391 \\
\hline$C 3$ & 0.1265 & 0.1267 & 0.1270 & 0.1272 & 0.1274 & 0.1276 & 0.1278 & 0.1280 & 0.1284 & 0.1286 \\
\hline$C 4$ & 0.1416 & 0.1418 & 0.1420 & 0.1422 & 0.1425 & 0.1427 & 0.1429 & 0.1432 & 0.1436 & 0.1439 \\
\hline$C 5$ & 0.1369 & 0.1371 & 0.1373 & 0.1376 & 0.1378 & 0.1380 & 0.1382 & 0.1385 & 0.1389 & 0.1391 \\
\hline C6 & 0.0988 & 0.0990 & 0.0991 & 0.0993 & 0.0995 & 0.0996 & 0.0998 & 0.0999 & 0.1003 & 0.1004 \\
\hline$C 7$ & 0.1255 & 0.1257 & 0.1259 & 0.1261 & 0.1263 & 0.1265 & 0.1267 & 0.1269 & 0.1273 & 0.1275 \\
\hline \multirow[t]{2}{*}{ C8 } & 0.1072 & 0.1074 & 0.1076 & 0.1077 & 0.1079 & 0.1081 & 0.1083 & 0.1084 & 0.1088 & 0.1090 \\
\hline & $\mathrm{Sc} 21$ & $\mathrm{Sc} 22$ & $\mathrm{Sc} 23$ & $\mathrm{Sc} 24$ & $\mathrm{Sc} 25$ & Sc26 & $\mathrm{Sc} 27$ & $\mathrm{Sc} 28$ & $\mathrm{Sc} 29$ & $\operatorname{Sc} 30$ \\
\hline$C 1$ & 0.1109 & 0.1095 & 0.1081 & 0.1067 & 0.1053 & 0.1038 & 0.1024 & 0.1010 & 0.0996 & 0.0981 \\
\hline$C 2$ & 0.1393 & 0.1396 & 0.1398 & 0.1400 & 0.1402 & 0.1405 & 0.1407 & 0.1409 & 0.1411 & 0.1414 \\
\hline$C 3$ & 0.1288 & 0.1290 & 0.1292 & 0.1294 & 0.1296 & 0.1298 & 0.1300 & 0.1302 & 0.1305 & 0.1307 \\
\hline$C 4$ & 0.1441 & 0.1443 & 0.1446 & 0.1448 & 0.1450 & 0.1452 & 0.1455 & 0.1457 & 0.1459 & 0.1462 \\
\hline$C 5$ & 0.1393 & 0.1396 & 0.1398 & 0.1400 & 0.1402 & 0.1405 & 0.1407 & 0.1409 & 0.1411 & 0.1414 \\
\hline C6 & 0.1006 & 0.1008 & 0.1009 & 0.1011 & 0.1012 & 0.1014 & 0.1016 & 0.1017 & 0.1019 & 0.1020 \\
\hline$C 7$ & 0.1277 & 0.1279 & 0.1281 & 0.1283 & 0.1286 & 0.1288 & 0.1290 & 0.1292 & 0.1294 & 0.1296 \\
\hline \multirow[t]{2}{*}{$C 8$} & 0.1091 & 0.1093 & 0.1095 & 0.1097 & 0.1098 & 0.1100 & 0.1102 & 0.1104 & 0.1105 & 0.1107 \\
\hline & $\mathrm{Sc} 31$ & $\mathrm{Sc} 32$ & $\mathrm{Sc} 33$ & $\mathrm{Sc} 34$ & $\mathrm{Sc} 35$ & Sc36 & $\mathrm{Sc} 37$ & $\mathrm{Sc} 38$ & Sc39 & Sc 40 \\
\hline $\mathrm{C} 1$ & 0.0967 & 0.0953 & 0.0939 & 0.0925 & 0.0910 & 0.0896 & 0.0882 & 0.0868 & 0.0853 & 0.0839 \\
\hline $\mathrm{C} 2$ & 0.1416 & 0.1418 & 0.1420 & 0.1422 & 0.1425 & 0.1427 & 0.1429 & 0.1431 & 0.1434 & 0.1436 \\
\hline C3 & 0.1309 & 0.1311 & 0.1313 & 0.1315 & 0.1317 & 0.1319 & 0.1321 & 0.1323 & 0.1325 & 0.1327 \\
\hline $\mathrm{C} 4$ & 0.1464 & 0.1466 & 0.1469 & 0.1471 & 0.1473 & 0.1475 & 0.1478 & 0.1480 & 0.1482 & 0.1485 \\
\hline C5 & 0.1416 & 0.1418 & 0.1420 & 0.1422 & 0.1425 & 0.1427 & 0.1429 & 0.1431 & 0.1434 & 0.1436 \\
\hline C6 & 0.1022 & 0.1024 & 0.1025 & 0.1027 & 0.1028 & 0.1030 & 0.1032 & 0.1033 & 0.1035 & 0.1036 \\
\hline $\mathrm{C} 7$ & 0.1298 & 0.1300 & 0.1302 & 0.1304 & 0.1306 & 0.1308 & 0.1310 & 0.1312 & 0.1314 & 0.1316 \\
\hline $\mathrm{C} 8$ & 0.1109 & 0.1111 & 0.1112 & 0.1114 & 0.1116 & 0.1118 & 0.1119 & 0.1121 & 0.1123 & 0.1125 \\
\hline
\end{tabular}

Consequently, the new weight values of criteria derived as per 40 scenarios are given in Table 18 and depicted in Fig. 3.

After the use of new criteria weights in the proposed approach, as presented in Fig. 4, the updated rankings of alternatives are provided via different scenarios. With respect to Fig. 4, it is obvious that alternatives $A 3, A 2$, and
A4 kept their ranks through all 40 scenarios. On the other hand, differentiation in the weight values of $C l$ has the most critical impact on the change in the rank of $A l$ and A5. A1 is third, while $A 5$ is fourth if $w_{1}$ is $w_{1} \in[0.1067,0.1408]$. Should $w_{1}$ is $w_{1} \in[0.0839,0.1053]$, however, $A 5$ is third, whereas A1 is fourth. In a nutshell, the rank order of alternatives $A l$ and $A 5$ changes with each other. In that their score functions are very close 
Fig. 3 Changes in criteria weights according to various scenarios

Fig. 4 Ranking of alternatives in the light of different scenarios
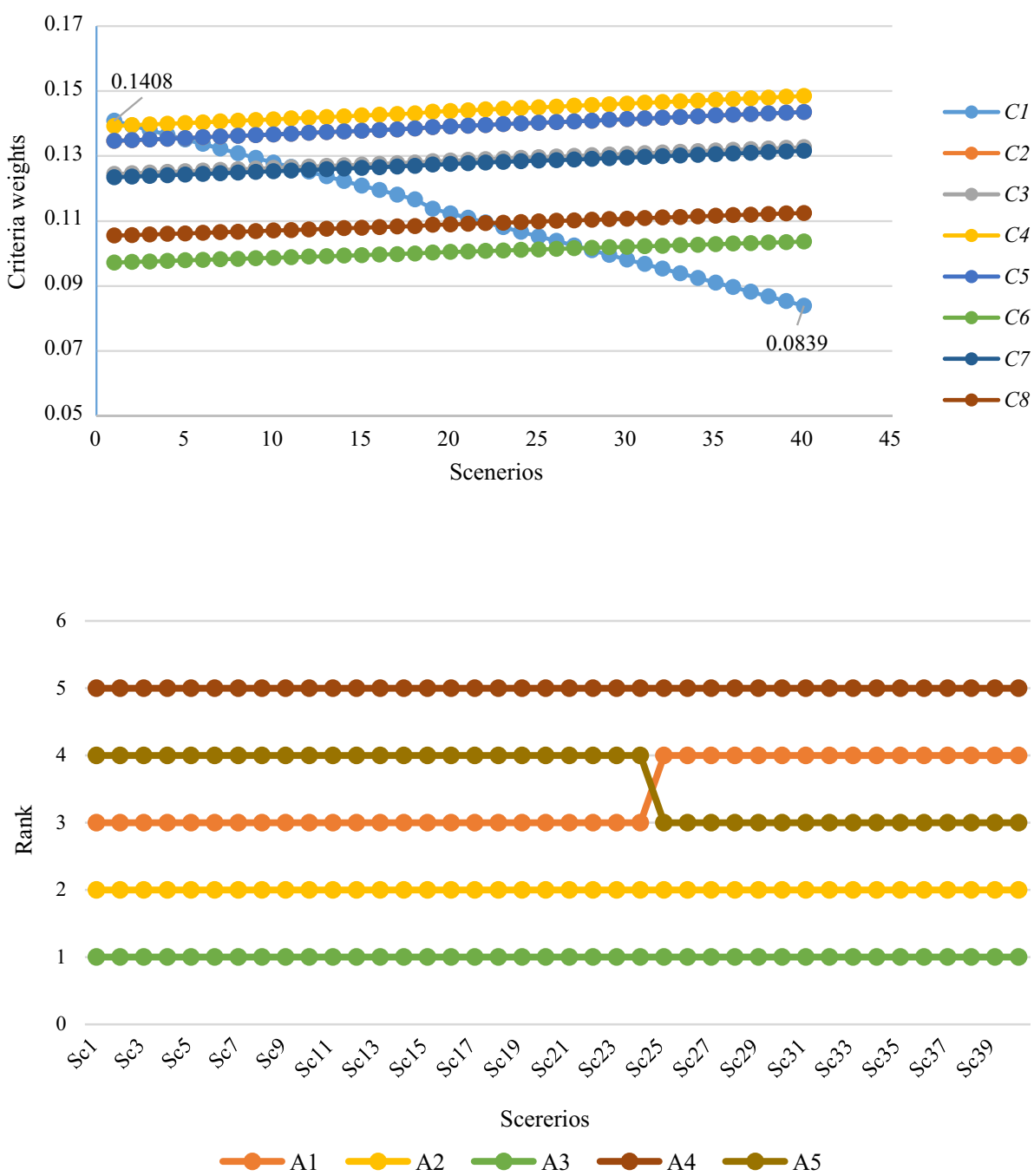

Table 19 Sensitivity analysis outcomes as per various importance weights of experts

\begin{tabular}{lll}
\hline Case & Scenarios & Ranking of alternatives \\
\hline Case 1 & Current situation & $\mathrm{A} 3 \succ \mathrm{A} 2 \succ \mathrm{A} 1 \succ \mathrm{A} 5 \succ \mathrm{A} 4$ \\
Case 2 & $w_{E 1}=w_{E 2}=w_{E 3}=w_{E 4}$ & $\mathrm{~A} 1 \succ \mathrm{A} 2 \succ \mathrm{A} 3 \succ \mathrm{A} 5 \succ \mathrm{A} 4$ \\
Case 3 & $w_{E 1}=0.7$, The rest 0.1 & $\mathrm{A} 2 \succ \mathrm{A} 3 \succ \mathrm{A} 1 \succ \mathrm{A} 5 \succ \mathrm{A} 4$ \\
Case 4 & $w_{E 2}=0.7$, The rest 0.1 & $\mathrm{A} 1 \succ \mathrm{A} 5 \succ \mathrm{A} 2 \succ \mathrm{A} 3 \succ \mathrm{A} 4$ \\
Case 5 & $w_{E 3}=0.7$, The rest 0.1 & $\mathrm{A} 3 \succ \mathrm{A} 1 \succ \mathrm{A} 2 \succ \mathrm{A} 5 \succ \mathrm{A} 4$ \\
Case 6 & $w_{E 4}=0.7$, The rest 0.1 & $\mathrm{A} 2 \succ \mathrm{A} 1 \succ \mathrm{A} 5 \succ \mathrm{A} 3 \succ \mathrm{A} 4$ \\
\hline
\end{tabular}

$(A 1=0.0947, A 5=0.1027)$, the change of ranking is no surprise. As a result, $A l$ and $A 5$ could be thought equally good alternatives. Nonetheless, the weight change of $C 1$ does not impact the ranking of the rest. According to the findings, therefore, alternative $A 3$ remains the best, followed by alternative $A 2$. Nevertheless, it is found that $A 4$ is

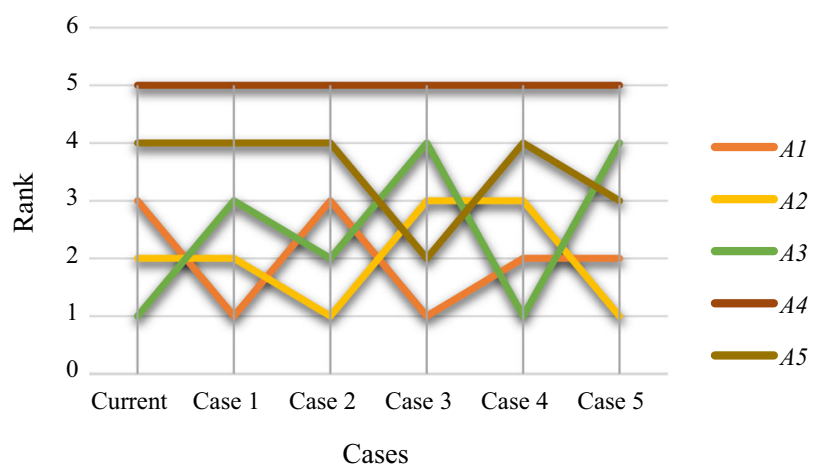

Fig. 5 Final ranking changes of alternatives

the worst alternative through all 40 scenarios. In spite of a little change in the ranking results, it can be concluded that the initial ranking (i.e., $A 3 \succ A 2 \succ A 1 \succ A 5 \succ A 4$ ) is approved and accepted. 
Table 20 Results of the IF-MARCOS approach

\begin{tabular}{llllllll}
\hline & $\mathrm{Si}$ & $\breve{K}_{i}^{-}$ & $\breve{K}_{i}^{+}$ & $f\left(\breve{K}_{i}^{-}\right)$ & $f\left(\breve{K}_{i}^{+}\right)$ & $f\left(\breve{K}_{i}\right)$ & Rank \\
\hline$A 1$ & 0.929 & 1.073 & 0.925 & 0.463 & 0.537 & 0.661 & 3 \\
$A 2$ & 0.923 & 1.077 & 0.929 & 0.463 & 0.537 & 0.664 & 2 \\
$A 3$ & 0.925 & 1.107 & 0.955 & 0.463 & 0.537 & 0.682 & 1 \\
$A 4$ & 0.911 & 1.057 & 0.911 & 0.463 & 0.537 & 0.651 & 5 \\
$A 5$ & 0.955 & 1.071 & 0.923 & 0.463 & 0.537 & 0.660 & 4 \\
\hline
\end{tabular}

\subsection{Changing the weight values of the experts}

Because the importance weights of experts directly affect the determination of alternative rankings, it is crucial to make an analysis of the influence of changes in their importance on the rank orders. The importance weights of the experts were calculated above as follows: $w_{E 1}=w_{E 3}=$ 0.269 and $w_{E 2}=w_{E 4}=0.231$. On the basis of the values obtained, we can conclude that the experts $E 1$ and $E 3$ have the most meaningful impact on the introduced frameworks' final outcomes.

To demonstrate the influences of several importance weights of all experts on the outcomes found by the IFMAIRCA framework in this research, six various cases are formed and evaluated the results as depicted in Table 19. In Case 1, the current importance weights of experts are addressed. All experts are handled to have the equal importance weight $(0.25)$ in Case 2. In the cases from 3 to 6 , a high weight $(0.7)$ is allocated to each expert, respectively, while a small weight $(0.1)$ is assigned to the remaining ones to satisfy the condition $\sum w_{E j}=1$. According to the sensitivity analysis, it is noticed that different importance weights of experts influence the ranking order of alternatives. For example, as depicted in Fig. 5, A3 is the alternative with the best performance in both Case 1 and Case 5. Similarly, $A 1$ is the most preferred alternative in two cases: 2 and 4. In both Cases 3 and 6, $A 2$ is the best alternative. These results emphasize that there is an effect of experts' importance weights on determining a suitable alternative.

\subsection{Benchmarking with the results of the IF- MARCOS approach}

In the last decade, it is noticeable that extended MCDM techniques with IFSs have been employed in making decisions. However, each of these approaches has its unique processes. To execute a comparison, MARCOS extensions of IFSs [31] are employed in this work to tackle the coronavirus vaccine selection problem. The detailed information regarding the IF-MARCOS can be found in Ecer and Pamucar's [31] study. Ranking results of the application of these approaches are presented in Table 20.

As per the findings derived, it is confirmed that alternative A3 demonstrates the most preferred option according to IF-MARCOS. Besides, the alternative A4 is placed last in the final ranking, whereas A2 is the second-best alternative. Obviously, the application of the introduced framework and IF-MARCOS give the same ranking order. Based on the above analysis and Fig. 6, it can be concluded that the final ranking result obtained with IF-MAIRCA is as reliable and useful as the outcomes obtained from the IFMARCOS model. It should note that the symmetrical structure in Fig. 6 is due to the fact that IF-MAIRCA identifies the smallest result as the best alternative, while IF-MARCOS emphasizes the highest result as the most
Fig. 6 Utility scores of IFMAIRCA and IF-MARCOS

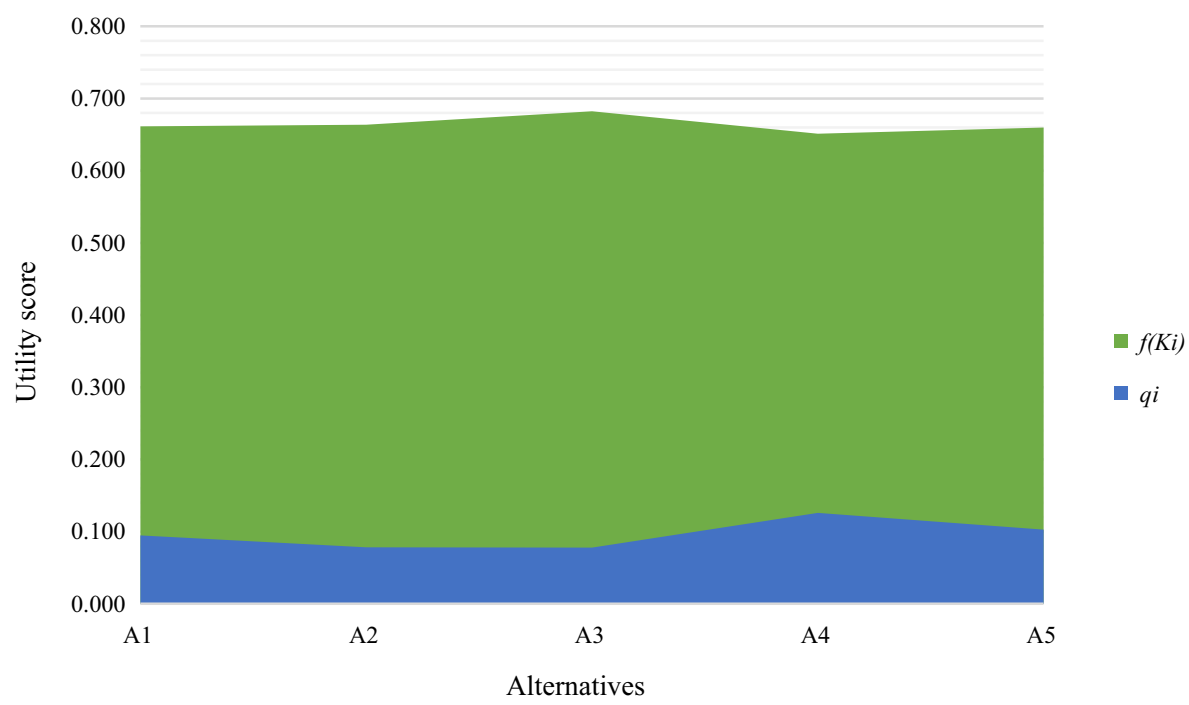


preferred. So, the proposed IF-MAIRCA model is as robust as the approach compared and can be used confidently in challenging real-world decision-making problems such as those managed by Kaya and Ertugrul [42], Precup et al. [66], and Yuhana et al. [98], among others.

\subsection{The effect of a change in linguistic assessments}

Besides, it is examined the effect of a change in linguistic assessments on the final decision. To achieve this, the linguistic assessments of $E 1$ as per the alternative $A 3$ in Table 6 were changed from EG, G, VVG, VG, EG, G, VVG, and VVG to G, G, G, G, G, G, G, and G. Such a change produces the following utility scores:

$q_{1}=0.0945, q_{2}=0.0776, q_{3}=0.0802, q_{4}=0.1281, q_{5}=0.1$

. A2 becomes the most acceptable alternative in this case, while $A 3$ is the second best. Thus, the proposed model is fairly sensitive to linguistic ratings.

\section{Managerial implications and limitations}

This work develops an MCGDM framework called IFMAIRCA, which goals to select the most preferable coronavirus vaccine among various vaccine options considering some conflicting criteria. This approach allows experts to express their thoughts, experiences, and knowledge with linguistic values and allows diverse persons to join by a strong method to come to a final decision. Because the MAIRCA method defines the gap between real and empirical outcomes successfully, a high performance could be accomplished in an uncertain environment by using it. Additionally, comparison and sensitivity check confirm the authority of the proposed framework.

With respect to the outcomes found in this research, thus, the most significant attribute for coronavirus vaccine selection is "duration of protection" with a relative weight of 0.1422 . The next attribute is "effectiveness of the vaccine" (0.1390). The next attributes for effective selection are both "success against the mutations" and "logistics" (0.1344). Further, the next attribute is "storage conditions" (0.1243) and followed by "side effects" (0.1232). The findings as well state that "price" $(0.1053)$ is ranked seventh. Finally, "number of vaccine doses" is the least crucial attribute. In relation to the findings, apart from this, coronavirus vaccines are prioritized from best to worst as AZD1222, mRNA-1273, Comirnaty, Sputnik V, and CoronaVac. The reason behind being the best coronavirus vaccine of AZD1222 over the rest could be its satisfactory protection duration, storage conditions, easy logistics, and low price.
The main contributions of the research are as follows.

- To model and analyze information with a high degree of fuzziness, for the first time in the literature, this work posits a new MCGDM methodology, named IFMAIRCA.

- IF-MAIRCA allows the preferred coronavirus vaccine to meet the necessities of not only authorities and experts but for consumers willing to purchase coronavirus vaccine.

- Bearing in mind the importance of experts, the proposed methodology determines the weight values of evaluation criteria and alternative rankings simultaneously, which makes it a useful decision tool.

- As far as the authors' knowledge, in the era of COVID19, integrating the MAIRCA method and IFS in the 6 context of coronavirus vaccine selection has not been studied.

- One of the unique properties of the introduced framework is that it takes the importance weight of each expert into account.

This research holds certain limitations. As there are still many uncertainties regarding the coronavirus, the criteria set is confined to the experts' knowledge. Further, a simple form of IFSs is addressed. Hezam et al. [37] argued that the decision-making team should be involved experts from different medical fields to get benefit from their knowledge in determining priorities and ratings. The proposed model, therefore, makes calculations based on the subjective evaluations of a team of experts in their fields. An assessment based on those regions can be made if experts are selected from different countries or continents. Children and older patient groups are generally not included from clinical trials. Therefore, there are no published data on the safety and efficacy of vaccines in children and the elderly [77]. As a result, this study considers people over 18 years old but younger than 65 years old in Turkey, which is another limitation. When we are conducting this work, no country had access to all vaccines approved. As a result of the admirable intensive vaccine development and production efforts, it is hoped that all countries will have access to various vaccines in the near future. So, it will be likely to test the effectiveness of the proposed model with actual applications for different age groups. Further work could be performed on interval-valued IFNs or trapezoidal IFNs.

\section{Conclusions}

Vaccines work together with the natural defenses of the human body to protect health and prevent disease so that when anybody is exposed, s/he is ready to fight the virus. 
Because the MAIRCA method is more effective in detecting vagueness with combined IFSs, this work introduces IF-MAIRCA framework in order to choose the finest coronavirus vaccine during the COVID-19 outbreak. The IF-MAIRCA methodology, which has not been proposed before, has a great chance of success in solving multicriteria problems as it can be operated easily. The introduced IF-MAIRCA methodology is effective in overcoming the ambiguity and uncertainty in experts' perceptions. Finally, the reliability and practicability of the introduced model are also checked with a three-phase sensitivity analysis. The primary goals of governments are to reduce deaths during the pandemic, remove obstacles to the speedy recovery of patients infected with COVID-19, and well-being for their people. So, the proposed methodology may give governments selecting the finest vaccine for their country.

As expected, this work also has some its own limitations. It can be noted that the importance weights of the evaluation criteria may vary for different countries and continents. Whereas storage conditions are less critical for a country in the Arctic, this criterion may be the most significant in a country in Africa. As a result, the criteria weights and vaccine rankings obtained in this study may vary from country to country. Since the beginning of the COVID-19 in China, many scholars around the world have declared predictions for the pandemic $[69,90]$ though the modeling results often differed from each other [70]. Because the methodology proposed in this paper is an assessment framework, not a prediction model, it is not possible to use the model to predict any stage of the epidemic (peak time, ending, etc.).

MAIRCA multi-criteria technique integrated with the IFS has a tremendous chance of success for MCGDM problems because it also takes uncertain and incomplete information of experts into account. Thus, in the future, this framework can be addressed for coping with fuzziness in MCDM problems like personnel selection, site selection, renewable energy source evaluation, and many other fields of engineering, management, agriculture, etc. problems.

\section{Appendix A: Coronavirus vaccines considered in this paper as alternatives}

\section{Comirnaty (A1)}

Comirnaty developed in collaboration with BioNTech and Pfizer companies is the first vaccine approved by WHO for emergency use. Comirnaty which is also referred to as BNT162b2 uses a new technology known as messenger RNA (mRNA). The goal is to turn the body's own cells into vaccine-producing structures. The vaccine makes cells produce copies of coronavirus proteins, which allows protective antibodies to be produced [32]. The primary analysis outcomes of the phase 3 trial stated that vaccine efficacy is $95 \%$ [22].

\section{mRNA-1273 (A2)}

The US-based pharmaceutical and biotechnology company Moderna is behind the mRNA-1273, which is an mRNA vaccine [57]. mRNA-1273, a second vaccine that received emergency use approval in the EU, has a number of advantages, given its manufacturing flexibility and efficiency. According to the primary analysis results of the phase 3 trial, furthermore, vaccine efficacy was determined by $94.1 \%$ for the 185 volunteers [12].

\section{AZD1222 (A3)}

Developed by Oxford University in England as well as manufactured and distributed by British pharmaceutical company Astra Zeneca, AZD1222 is a viral vector vaccine using an attenuated version of a common cold virus found in chimps. Using gene technology in viral vector vaccines, some of the genetic material carried by the virus is inserted into another virus and injected into the body [7]. The fact that AZD1222 can be stored between 2 and $8{ }^{\circ} \mathrm{C}$ allows its easy distribution.

\section{CoronaVac (A4)}

CoronaVac, which is a more traditional method of vaccine and developed by Sinovac pharmaceutical company in China, is an inactivated vaccine against COVID-19 [76]. In inactivated vaccines, viruses that cause infection are injected into the body by weakening or inactivating them. Thus, the body learns to fight against the virus that cannot harm itself and gains immunity.

\section{Sputnik V (A5)}

Sputnik V, a viral vector vaccine, was developed by the Gamaleya Research Institute in Russia in August 2020. It is the first COVID-19 vaccine recommended for general use against COVID-19 in the world. It can be stored at a temperature of 2 to $8{ }^{\circ} \mathrm{C}$, which allows for easy distribution globally [78].

\section{Declaration}

Conflict of interest No conflict of interest exits in the submission of this manuscript. 


\section{References}

1. Abdullah L, Najib L (2016) A new preference scale MCDM method based on interval-valued intuitionistic fuzzy sets and the analytic hierarchy process. Soft Comput 20(2):511-523

2. Adar T, Delice EK (2019) New integrated approaches based on MC-HFLTS for healthcare waste treatment technology selection. J Enterprise Inform Manag 32(4):688-711

3. Adar T, Kilic Delice E (2019) An integrated MCHFLTS\&MAIRCA method and application in cargo distribution companies. Int J Supply Oper Manag 6(3):276-281

4. Aloini D, Dulmin R, Mininno V (2014) A peer IF-TOPSIS based decision support system for packaging machine selection. Exp Syst Appl 41(5):2157-2165

5. Alrasheedi M, Mardani A, Mishra AR, Streimikiene D, Liao H, Al-nefaie AH (2021) Evaluating the green growth indicators to achieve sustainable development: a novel extended intervalvalued intuitionistic fuzzy-combined compromise solution approach. Sustain Develop 29(1):120-142

6. Ashtiani B, Haghighirad F, Makui A, Ali Montazer G (2009) Extension of fuzzy TOPSIS method based on interval-valued fuzzy sets. Appl Soft Comput 9(2):457-461

7. AstraZeneca (2020) AZD1222 vaccine met primary efficacy endpoint in preventing COVID-19. https://www.astrazeneca. com/media-centre/press-releases/2020/azd1222hlr.html. Accessed 30 Dec 2020.

8. Atanassov KT (1999) Intuitionistic fuzzy sets: theory and applications. Springer, New York

9. Atanassov KT (1983) Intuitionistic fuzzy sets, VII ITKR Session, Sofia, 20-23 June 1983 (Deposed in Centr. Sci.-Techn. Library of the Bulg. Acad. of Sci., 1697/84) (in Bulgarian).

10. Atanassov KT (2012) On intuitionistic fuzzy sets theory. Springer, New York

11. Ayçin E, Güçlü P (2020) BIST ticaret endeksinde yer alan işletmelerin finansal performanslarının Entropi ve MAIRCA yöntemleri ile değerlendirilmesi. Muhasebe ve Finansman Dergisi 85:287-312

12. Baden LR, El Sahly HM, Essink B, Kotloff K, Frey S, Novak R et al (2021) Efficacy and safety of the mRNA-1273 SARS-CoV2 vaccine. N Engl J Med 384(5):403-416

13. Bagheri R, Borouji Z, Razavian SB, Keshvari MM, Sharifi F, Sharifi S (2021) Implementation of MCDM-based integrated approach to identifying the uncertainty factors on the constructional project. Math Prob Eng

14. Baležentis T, Zeng S, Baležentis A (2014) MULTIMOORAIFN: a MCDM method based on intuitionistic fuzzy number for performance management. Econ Comput Econ Cybern Stud Res 48(4)

15. Boral S, Howard I, Chaturvedi SK, McKee K, Naikan VNA (2020) An integrated approach for fuzzy failure modes and effects analysis using fuzzy AHP and fuzzy MAIRCA. Eng Fail Anal 108:104195

16. Boran FE, Genç S, Kurt M, Akay D (2009) A multi-criteria intuitionistic fuzzy group decision making for supplier selection with TOPSIS method. Exp Syst Appl 36(8):11363-11368

17. Boran FE, Kurtuluş B, Menlik T (2012) The evaluation of renewable energy technologies for electricity generation in Turkey using intuitionistic fuzzy TOPSIS. Energy Sour B Econ Plan Policy 7(1):81-90

18. Bouazzaoui A, Abdellatif AA, Al-Allaf FA, Bogari NM, AlDehlawi S, Qari SH (2021) Strategies for vaccination: conventional vaccine approaches versus new-generation strategies in combination with adjuvants. Pharmaceutics 13(2):140

19. Böyükaslan A, Ecer F (2021) Determination of drivers for investing in cryptocurrencies through a fuzzy full consistency
method-Bonferroni (FUCOM-F'B) framework. Technol Soc 67:101745

20. Büyüközkan G, Göçer F (2017) Application of a new combined intuitionistic fuzzy MCDM approach based on axiomatic design methodology for the supplier selection problem. Appl Soft Comput 52:1222-1238

21. Çalı S, Balaman ŞY (2019) A novel outranking based multi criteria group decision making methodology integrating ELECTRE and VIKOR under intuitionistic fuzzy environment. Exp Syst Appl 119:36-50

22. Cavaleri M, Enzmann H, Straus S, Cooke E (2021) The European medicines agency's EU conditional marketing authorisations for COVID-19 vaccines. Lancet 397(10272):355-357

23. Chai J, Liu JN, Xu Z (2012) A new rule-based SIR approach to supplier selection under intuitionistic fuzzy environments. Int J Uncert Fuzziness Knowl Based Syst 20(03):451-471

24. Chatterjee K, Pamucar D, Zavadskas EK (2018) Evaluating the performance of suppliers based on using the R'AMATELMAIRCA method for green supply chain implementation in electronics industry. J Clean Prod 184:101-129

25. Deutsche WT (2021) Korona aşısının riskleri ve yan etkileri. https://www.dw.com/tr/korona-a\%C5\%9F\%C4\%B1s\%C4\%B1n $\% \mathrm{C} 4 \%$ B 1n-riskleri-ve-yan-etkileri/a-56140550. Accessed on 28 Jan 2021

26. Devi K, Yadav SP (2013) A multicriteria intuitionistic fuzzy group decision making for plant location selection with ELECTRE method. Int $\mathbf{J}$ Adv Manuf Technol 66(9-12):1219-1229

27. Ecer F (2018) Third-party logistics (3PLs) provider selection via Fuzzy AHP and EDAS integrated model. Technol Econ Develop Econ 24(2):615-634

28. Ecer F (2020b) Multi-criteria decision making for green supplier selection using interval type-2 fuzzy AHP: a case study of a home appliance manufacturer. Oper Res 1-35

29. Ecer F (2021) Sustainable supplier selection: FUCOM subjective weighting method based MAIRCA approach. J Mehmet Akif Ersoy Univ Econ Admin Sci Faculty 8(1):26-48

30. Ecer F, Pamucar D (2020) Sustainable supplier selection: A novel integrated fuzzy best worst method (F-BWM) and fuzzy CoCoSo with Bonferroni (CoCoSo'B) multi-criteria model. J Clean Prod 266:121981

31. Ecer F, Pamucar D (2021) MARCOS technique under intuitionistic fuzzy environment for determining the COVID-19 pandemic performance of insurance companies in terms of healthcare services. Appl Soft Comput 104

32. EMA (2021) Comirnaty: EPAR. https://www.ema.europa.eu/en/ documents/product-information/comirnaty-epar-product-informa tion_en.pdf. Accessed on 30 Jan 2021

33. Gigović L, Pamučar D, Bajić Z, Milićević M (2016) The combination of expert judgment and GIS-MAIRCA analysis for the selection of sites for ammunition depots. Sustainability 8(4):372

34. Gul M, Ak MF (2020) Assessment of occupational risks from human health and environmental perspectives: a new integrated approach and its application using fuzzy BWM and fuzzy MAIRCA. Stochast Environ Res Risk Assess 34(8):1231-1262

35. Gumus S, Kucukvar M, Tatari O (2016) Intuitionistic fuzzy multi-criteria decision making framework based on life cycle environmental, economic and social impacts: The case of US wind energy. Sustain Prod Consump 8:78-92

36. Günay F, Ecer F (2020) Cash flow based financial performance of Borsa İstanbul tourism companies by Entropy-MAIRCA integrated model. J Multidiscip Acad Tour 5(1):29-37

37. Hezam IM, Nayeem MK, Foul A, Alrasheedi AF (2021) COVID-19 Vaccine: a neutrosophic MCDM approach for determining the priority groups. Results Phys 20:103654 
38. Joshi D, Kumar S (2014) Intuitionistic fuzzy entropy and distance measure based TOPSIS method for multi-criteria decision making. Egypt Inform J 15(2):97-104

39. Kahraman C, Keshavarz Ghorabaee M, Zavadskas EK, Cevik Onar S, Yazdani M, Oztaysi B (2017) Intuitionistic fuzzy EDAS method: an application to solid waste disposal site selection. J Environ Eng Landsc Manag 25(1):1-12

40. Karagoz S, Deveci M, Simic V, Aydin N, Bolukbas U (2020) A novel intuitionistic fuzzy MCDM-based CODAS approach for locating an authorized dismantling center: a case study of Istanbul. Waste Manag Res 38(6):660-672

41. Karaşan A, Kaya İ, Erdoğan M (2020) Location selection of electric vehicles charging stations by using a fuzzy MCDM method: a case study in Turkey. Neural Comput Appl 32(9):4553-4574

42. Kaya Y, Ertuğrul ÖF (2019) Estimation of neurological status from non-electroencephalography bio-signals by motif patterns. Appl Soft Comput 83:105609

43. Khurana A, Allawadhi P, Khurana I, Allwadhi S, Weiskirchen R, Banothu AK et al (2021) Role of nanotechnology behind the success of mRNA vaccines for COVID-19. Nano Today 38:101142

44. Krohling RA, Pacheco AG, Siviero AL (2013) IF-TODIM: an intuitionistic fuzzy TODIM to multi-criteria decision making. Knowl Based Syst 53:142-146

45. Kucukvar M, Gumus S, Egilmez G, Tatari O (2014) Ranking the sustainability performance of pavements: an intuitionistic fuzzy decision making method. Autom Const 40:33-43

46. Kumar S, Haleem A (2019) Assessing innovativeness of manufacturing firms using an intuitionistic fuzzy based MCDM framework. Benchmark Int J 26:1823

47. Li M, Jin L, Wang J (2014) A new MCDM method combining QFD with TOPSIS for knowledge management system selection from the user's perspective in intuitionistic fuzzy environment. Appl Soft Comput 21:28-37

48. Liao H, Mi X, Xu Z, Xu J, Herrera F (2018) Intuitionistic fuzzy analytic network process. IEEE Trans Fuzzy Syst 26(5):2578-2590

49. Liu S, Hu Y, Zhang X, Li Y, Liu L (2020) Blockchain service provider selection based on an integrated BWM-entropy-TOPSIS method under an intuitionistic fuzzy environment. IEEE Access 8:104148-104164

50. Liu Y, Liu J, Xia H, et al (2021) BNT162b2-elicited neutralization against new SARS-CoV-2 spike variants. N Engl J Med

51. Long S, Geng S (2015) Decision framework of photovoltaic module selection under interval-valued intuitionistic fuzzy environment. Energy Conv Manag 106:1242-1250

52. Majumder P, Baidya D, Majumder M (2021) Application of novel intuitionistic fuzzy BWAHP process for analysing the efficiency of water treatment plant. Neural Comput Appl 1-17

53. Maqbool A, Khan NZ (2020) Analyzing barriers for implementation of public health and social measures to prevent the transmission of COVID-19 disease using DEMATEL method. Diab Metab Synd Clin Res Rev 14(5):887-892

54. Mishra AR, Rani P (2018) Interval-valued intuitionistic fuzzy WASPAS method: application in reservoir flood control management policy. Group Decis Negot 27(6):1047-1078

55. Mishra AR, Mardani A, Rani P, Kamyab H, Alrasheedi M (2021) A new intuitionistic fuzzy combinative distance-based assessment framework to assess low-carbon sustainable suppliers in the maritime sector. Energy 237:121500

56. Mishra AR, Rani P, Pandey K, Mardani A, Streimikis J, Streimikiene D, Alrasheedi M (2020) Novel multi-criteria intuitionistic fuzzy SWARA-COPRAS approach for sustainability evaluation of the bioenergy production process. Sustainability 12(10):4155
57. Moderna (2021) mRNA platform: enabling drug discovery and development. https://www.modernatx.com/mrna-technology/ mrna-platform-enabling-drug-discovery-development. Accessed 11 Feb 2021.

58. Oldenburg J, Klamroth R, Langer F, Albisetti M, von Auer C, Ay C, et al (2021) Diagnosis and management of vaccine-related thrombosis following AstraZeneca COVID-19 vaccination: guidance statement from the GTH. Hämostaseologie 1-5

59. Özçil A, Tuş A, Öztaş GZ, Adalı EA, Öztaş T (2020) The novel integrated model of plithogenic sets and MAIRCA method for MCDM problems. International conference on intelligent and fuzzy systems. Springer, Cham, pp 733-741

60. Pamučar DS, Ćirović G, Božanić D (2019) Application of interval valued fuzzy-rough numbers in multi-criteria decision making: the IVFRN-MAIRCA model. Yugoslav J Oper Res 29(2):221-247

61. Pamucar DS, Pejcic Tarle S, Parezanovic T (2018) New hybrid multi-criteria decision-making DEMATELMAIRCA model: sustainable selection of a location for the development of multimodal logistics centre. Econ Res Ekonomska istraživanja 31(1):1641-1665

62. Pamucar D, Ecer F (2020) Prioritizing the weights of the evaluation criteria under fuzziness: the fuzzy full consistency method-FUCOM-F. Facta Universitatis Ser Mech Eng 18(3):419-437

63. Pamucar D, Ecer F, Deveci M (2021) Assessment of alternative fuel vehicles for sustainable road transportation of United States using integrated fuzzy FUCOM and neutrosophic fuzzy MARCOS methodology. Sci Total Environ 788:147763

64. Pamučar D, Mihajlović M, Obradović R, Atanasković P (2017) Novel approach to group multi-criteria decision making based on interval rough numbers: Hybrid DEMATEL-ANP-MAIRCA model. Exp Syst Appl 88:58-80

65. Pamucar D, Vasin L, Lukovac L (2014). Selection of railway level crossings for investing in security equipment using hybrid DEMATEL-MARICA model. In: XVI International Scientificexpert Conference on Railway, Railcon, pp. 89-92

66. Precup RE, Teban TA, Albu A, Borlea AB, Zamfirache IA, Petriu EM (2020) Evolving fuzzy models for prosthetic hand myoelectric-based control. IEEE Trans Instrum Meas 69(7):4625-4636

67. Rani P, Jain D, Hooda DS (2019) Extension of intuitionistic fuzzy TODIM technique for multi-criteria decision making method based on Shapley weighted divergence measure. Granular Comput 4(3):407-420

68. Rani P, Mishra AR, Ansari MD, Ali J (2021) Assessment of performance of telecom service providers using intuitionistic fuzzy grey relational analysis framework (IF-GRA). Soft Comput 25(3):1983-1993

69. Read JM, Bridgen JR, Cummings DA, Ho A, Jewell CP (2020) Novel coronavirus 2019-nCoV: early estimation of epidemiological parameters and epidemic predictions. MedRxiv.

70. Roda WC, Varughese MB, Han D, Li MY (2020) Why is it difficult to accurately predict the COVID-19 epidemic? Infect Dis Model 5:271-281

71. Rouyendegh BD, Yildizbasi A, Üstünyer P (2020) Intuitionistic fuzzy TOPSIS method for green supplier selection problem. Soft Comput 24(3):2215-2228

72. Sanders B, Koldijk M, Schuitemaker H (2015) Inactivated viral vaccines. Vaccine analysis: strategies, principles, and control. Springer, Berlin, Heidelberg, pp 45-80

73. Schitea D, Deveci M, Iordache M, Bilgili K, Akyurt IZ, Iordache I (2019) Hydrogen mobility roll-up site selection using intuitionistic fuzzy sets based WASPAS, COPRAS and EDAS. Int J Hydrogen Energy 44(16):8585-8600 
74. Sen DK, Datta S, Mahapatra SS (2018) Sustainable supplier selection in intuitionistic fuzzy environment: a decision-making perspective. Benchmark Int J 25:545-574

75. Shen F, Ma X, Li Z, Xu Z, Cai D (2018) An extended intuitionistic fuzzy TOPSIS method based on a new distance measure with an application to credit risk evaluation. Inform Sci 428:105-119

76. Sinovac (2021) Supply vaccines to eliminate human diseases. http://www.sinovac.com/?optionid=754. Accessed on 15 Jan 2021.

77. Soiza RL, Scicluna C, Thomson EC (2021) Efficacy and safety of COVID-19 vaccines in older people. Age Ageing 50(2):279-283

78. Sputnik V (2021) General information. https://sputnikvaccine. com/about-vaccine/. Accessed on 29 Jan 2021

79. Stanujkić D, Karabašević D (2018) An extension of the WASPAS method for decision-making problems with intuitionistic fuzzy numbers: a case of website evaluation. Oper Res Eng Sci Theory Appl 1(1):29-39

80. Szmidt E, Kacprzyk J (2000) Distances between intuitionistic fuzzy sets. Fuzzy Sets Syst 114(3):505-518

81. Tan C (2011) A multi-criteria interval-valued intuitionistic fuzzy group decision making with Choquet integral-based TOPSIS. Exp Syst Appl 38(4):3023-3033

82. Tian ZP, Zhang HY, Wang JQ, Wang TL (2018) Green supplier selection using improved TOPSIS and best-worst method under intuitionistic fuzzy environment. Informatica 29(4):773-800

83. Traneva V, Atanassova V, Tranev S (2019) Index matrices as a decision-making tool for job appointment. In: Nikolov G, Kolkovska N, Georgiev K (eds) Numerical methods and applications. NMA 2018. Lecture notes in computer science, vol 11189. Springer, Cham, pp 158-166

84. Traneva V, Tranev S, Atanassova V (2020) Index matrices as a cost optimization tool of resource provisioning in uncertain cloud computing environment. In: Fidanova S (ed) Recent advances in computational optimization, studies in computational intelligence, vol 838. Springer, Cham, pp 155-179

85. Ulutaş A (2019) SWARA ve MAIRCA yöntemleri ile catering firması seçimi. Bus Manag Stud Int J 7(4):1467-1479

86. Wan SP, Wang F, Dong JY (2016) A novel group decision making method with intuitionistic fuzzy preference relations for RFID technology selection. Appl Soft Comput 38:405-422

87. Wang Z, Li KW, Xu J (2011) A mathematical programming approach to multi-attribute decision making with interval-valued intuitionistic fuzzy assessment information. Exp Syst Appl 38(10): 12462-12469

88. WHO (2021) COVID-19 vaccines. https://www.who.int/emer gencies/diseases/novel-coronavirus-2019/covid-19-vaccines. Accessed on 15 Feb 2021

89. Wu J (2015) A SD-IITFOWA operator and TOPSIS based approach for MAGDM problems with intuitionistic trapezoidal fuzzy numbers. Technol Econ Develop Econ 21(1):28-47
90. Wu JT, Leung K, Leung GM (2020) Nowcasting and forecasting the potential domestic and international spread of the 2019-nCoV outbreak originating in Wuhan, China: a modelling study. Lancet 395(10225):689-697

91. Xiong L, Zhong S, Liu S, Zhang X, Li Y (2020) An approach for resilient-green supplier selection based on WASPAS, BWM, and TOPSIS under intuitionistic fuzzy sets. Math Prob Eng

92. Xu Z (2007) Intuitionistic fuzzy aggregation operators. IEEE Trans Fuzzy Syst 15(6):1179-1187

93. Xue YX, You JX, Lai XD, Liu HC (2016) An interval-valued intuitionistic fuzzy MABAC approach for material selection with incomplete weight information. Appl Soft Comput 38:703-713

94. Ye F (2010) An extended TOPSIS method with interval-valued intuitionistic fuzzy numbers for virtual enterprise partner selection. Exp Syst Appl 37(10):7050-7055

95. Yener Y, Can GF (2021) A fmea based novel intuitionistic fuzzy approach proposal: intuitionistic fuzzy advance mcdm and mathematical modeling integration. Exp Syst Appl 115413

96. Yeni FB, Özçelik G (2019) Interval-valued Atanassov intuitionistic Fuzzy CODAS method for multi criteria group decision making problems. Group Decis Negot 28(2):433-452

97. Yue Z, Jia Y (2013) An application of soft computing technique in group decision making under interval-valued intuitionistic fuzzy environment. Appl Soft Comput 13(5):2490-2503

98. Yuhana UL, Fanani NZ, Yuniarno EM, Rochimah S, Koczy LT, Purnomo MH (2020) Combining fuzzy signature and rough sets approach for predicting the minimum passing level of competency achievement. Int J Artif Intell 18:237-249

99. Zadeh LA (1965) Information and control. Fuzzy Sets, 8(3), 338-353

100. Zhang C, Chen C, Streimikiene D, Balezentis T (2019) Intuitionistic fuzzy MULTIMOORA approach for multi-criteria assessment of the energy storage technologies. Appl Soft Comput 79:410-423

101. Zhang SF, Liu SY (2011) A GRA-based intuitionistic fuzzy multi-criteria group decision making method for personnel selection. Exp Syst Appl 38(9):11401-11405

102. Zhao J, You XY, Liu HC, Wu SM (2017) An extended VIKOR method using intuitionistic fuzzy sets and combination weights for supplier selection. Symmetry 9(9):169

103. Ziquan X, Jiaqi Y, Naseem MH, Zuquan X, Xueheng L (2021) Supplier selection of shipbuilding enterprises based on intuitionistic fuzzy multicriteria decision. Math Prob Eng 2021:1-11

104. Zolfani SH, Ecer F, Pamučar D, Raslanas S (2020) Neighborhood selection for a newcomer via a novel BWM-based revised MAIRCA integrated model: a case from the Coquimbo-La Serena conurbation. Chile Int J Strat Prop Manag 24(2):102-118

Publisher's Note Springer Nature remains neutral with regard to jurisdictional claims in published maps and institutional affiliations. 